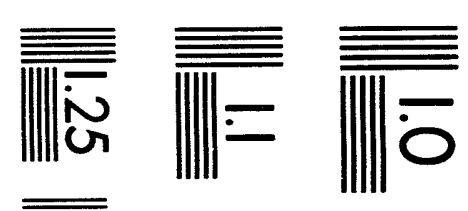

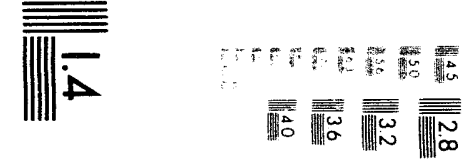

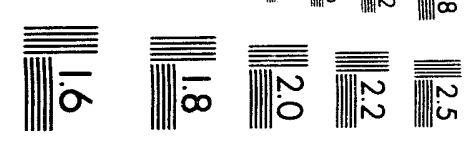



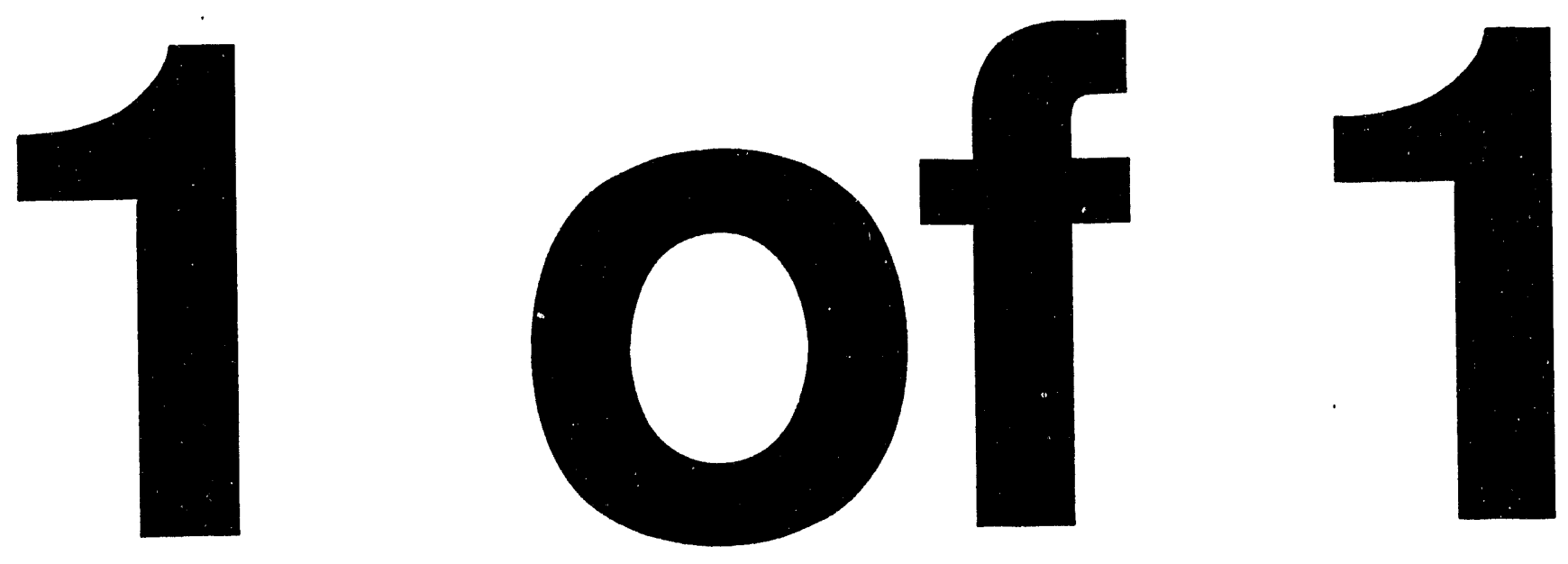
Risk Analysis Section

Health Sciences Research Division

\title{
Cost Estimates for the Uranium-in-Soils Integrated Demonstration Field Screening Technologies
}

\author{
Douglas M. Douthat \\ Anthony Q. Armstrong
}

Beth Ladd ${ }^{1}$

Date Published-September 1993

Prepared for the

Office of Technology Development

(EW 401040 0)

\author{
Prepared by the \\ OAK RIDGE NATIONAL LABORATORY \\ Oak Ridge, Tennessee 37831-6285 \\ managed by \\ MARTIN MARIETTA ENERGY SYSTEMS, INC. \\ for the \\ U.S. DEPARTMENT OF ENERGY \\ under contract DE-AC05-84OR21400
}

${ }^{1}$ University of Tennessee, Knoxville 
CONTENTS

Page

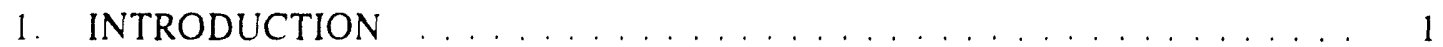

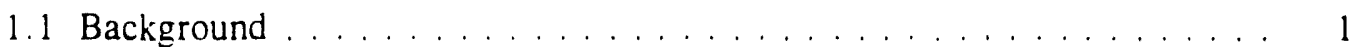

1.2 Objective ........................... 1

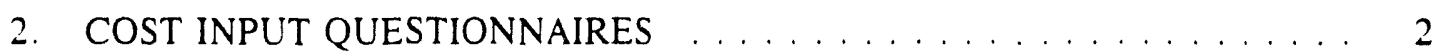

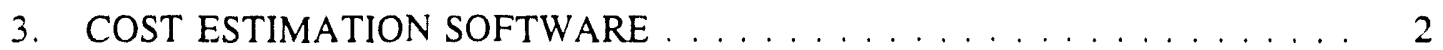

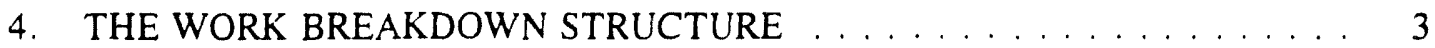

5. ASSUMPTIONS FOR THE COST ANALYSIS REPORTS . . . . . . . . 7

6. EXPECTED COSTS FOR THE FIELD SCREENING TECHNOLOGIES . . . . 11

6.1 Beta Scintillation Detector . . . . . . . . . . . . . . . . . . . . . . 13

6.2 In Situ Gamma Detector . . . . . . . . . . . . . . . . . . . . . . . . 13

6.3 Long-Range Alpha Detector . . . . . . . . . . . . . . . . . . 14

6.4 Mobile LA-ICP/AES Laboratory . . . . . . . . . . . . . . . . . 15

7. SCENARIO EVALUATIONS FOR THE FIELD SCREENING

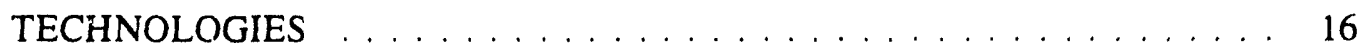

7.1 Beta Scintillation Detector . . . . . . . . . . . . . . . . . . . . . . 17

7.2 In Situ Gamma Detector . . . . . . . . . . . . . . . . . . . . . . . 18

7.3 Long-Range Alpha Detector . . . . . . . . . . . . . . 21

7.4 Mobile LA-ICP/AES Laboratory . . . . . . . . . . . . . . . . 22

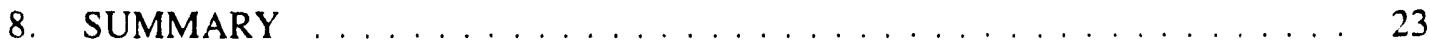

APPENDIX A COST ANALYSIS REPORTS FOR THE FIELD SCREENING TECHNOLOGIES 


\section{LIST OF FIGLRES}

Page

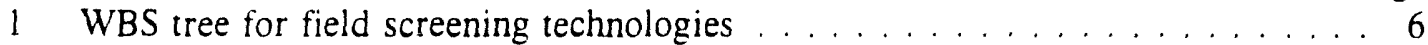

\section{LIST OF EXHIBITS}

Page

Page 1 of the long-range alpha detector take-off extension report . . . . . . . . 4

2 General cost summary-long-range alpha detector

\section{LIST OF TABLES}

$\begin{array}{lll}1 & \text { Expected costs for the field screening technologies } \ldots \ldots \ldots \ldots \ldots \ldots \ldots & \ldots \ldots \ldots \\ 2 & \text { Scenario evaluation-cost per sample } \ldots \ldots \ldots \ldots & \ldots \ldots \ldots \ldots\end{array}$




\section{INTRODUCTION}

\subsection{BACKGROUND}

The principal objective of the Uranium-in-Soils Integrated Demonstration (ID) is to develop an optimum integrated system of technologies for the removal of uranium substances from soil, which, through demonstration, has been proven in terms of cost reduction. waste minimization. risk reduction, and user applicability. The Performance Assessment Group furnishes a systematic evaluation process for the ID, provides information to support decision-making for future applications, and establishes whether the technologies are successful. The field screening technologies developed by the Characterization Group must be evaluated by the Performance Assessment Group for their adequacy in detecting uranium contamination. Sandia National Laboratory (SNL) is tasked to develop and apply the technical tools necessary to evaluate the field screening technologies within a cost/risk decision-making framework under the Technical Task Plan (TTP), "Cost/Risk Performance Assessment of Soil Characterization" (TTP AL231007). In support of this TTP, Performance Assessment Group members at the Oak Ridge National Laboratory (ORNL) developed cost estimates for the uranium field screening technologies, satisfying the first step in SNL's cost/risk performance evaluation process.

\subsection{OBJECTIVE}

The objective of this document is to describe the work conducted by the ORNL Performance Assessment Group members responsible for developing the cost analysis reports. The following information is provided in this report: 1) an explanation of the cost input questionraires, which were sent to the developers of the field screening technologies and used by the cost estimator to acquire information and develop the cost estimates, 2) a description of the computer software package chosen to create the cost estimates, as well as why it was chosen, 3) a description of how the Uranium-in-Soils ID project is broken down structurally in terms of a work breakdown structure (WBS) for the cost estimates, 4) an explanation of the assumptions made by the cost estimator in developing the cost estimates, 5) a summary of the expected costs for each field screening technology, and 6) an explanation of how the cost analysis reports for a scenario evaluation (provided in the cost input questionnaires) were derived, as well as a summary of the scenario evaluation costs for each technology. 


\section{COST INPUT QUESTIONNAIRES}

Cost input questionnaires were developed by the Performance Assessment Group and sent to developers of the four field screening technologies for the Uranium-in-Soils ID. To develop accurate and useful cost analysis reports, detailed cost estimates associated with constructing, operating, and maintaining the field screening equipment were necessary and were provided by the developers in the cost input questionnaires. A scenario evaluation was also included in the questionnaire to determine the cost to adequately characterize a hypothetical 1 -acre site in a given timeframe.

Once these questionnaires were completed and returned to Performance Assessment Group members, cost estimates were created using COSTPRO and the Martin Marietta Energy Systems. Inc. (Energy Systems) Automated Estimating System (AES). The AES and COSTPRO software programs both act as spreadsheets which rely on the cost estimator for all cost inputs. Therefore, the estimator must be familiar with the relevant technologies to produce accurate cost estimates. After review of the cost analysis reports produced by the AES and COSTPRO programs, it was determined that COSTPRO would be the best software package to use for producing cost reports. The AES program, originally developed by the Energy Systems' Engineering Division for construction cost estimates, contains many lines that apply to Energy Systems' cost system only, which could lead to confusion if AES is the chosen system for the Uranium-in-Soils ID. In addition, COSTPRO is easier to revise and manipulate if revisions to the cost reports are necessary in the future.

\section{COST ESTIMATION SOFTWARE}

COSTPRO was the computer software package used to create the Uranium-in-Soils ID field screening technologies cost estimates shown in Appendix A. COSTPRO is a fully developed generic cost-estimating system that can be used to prepare cost estimates on projects from the planning stage through detailed design. The underlying approach is to use unit costs rather than historical costs. COSTPRO can be used for all types of wastes. including hazardous chemicals, mixed wastes, and radioactive wastes, and for all phases of environmental restoration work, including remedial investigations, feasibility studies, and remedial design and construction. The 
code is a complete PC-based. commercial rewrite of the Los Alamos National Laboratory's (LANL's) cost estimating system: therefore. it is particularly well adapted for preparing cost estimates of U.S. Department of Energy (DOE) projects. The program is written in Fortran/CLanguage and runs on a standard IBM-AT compatible or 386 with math coprocessor.

The program creates two basic files: 1) a take-off file that contains a description of the items to be costed, as well as the quantity and material, equipment, and labor costs for each item and 2) a project factors file that contains the descriptions of WBS codes and markups to be applied to the project. The COSTPRO report generation file references the information in the take-off and project factors files to create the report specified by the estimator. The reports, which can be generated through COSTPRO's sort schemes, are numerous and include several that the estimator can design according to project-specific requirements. The take-off extension report compiles the appropriate take-off items and provides the direct costs for the project, sorted and subtotaled according to the cost estimator's preference (see page 1 of the take-off extension report for the long-range alpha detector presented in Exhibit 1). The general cost summary (shown in Exhibit 2) applies the direct, general, and project markups (e.g., labor, overhead, profit, escalation, contingency, etc.) that are stored in the project factors file to the direct costs to obtain the project's total costs. The general cost summary can also be sorted and subtotaled according to the estimator's preference.

\section{THE WORK BREAKDOWN STRUCTURE}

The function of a WBS tree is to show the structural breakdown of a project. A schematic representation of the WBS for the Uranium-in-Soils ID field screening technologies, shown in Fig. 1, was developed by the cost estimator. This WBS represents the total expected costs of the four technologies. The first breakdown occurs into the Level 1 categories. Subsequently, these categories are further broken down into the subcategories of Level 2, Level 3, etc. COSTPRO allows the estimator to build personal WBSs from one or more of four WBSs provided by COSTPRO (Exhibit 1). For this project, the cost estimator arbitrarily used WBS 1 in COSTPRO to identify and categorize the characterization technologies. For the take-off items that define the expected costs of the technologies, WBS 3 was used to aid the estimator and anyone looking at the report to identify a specific technology (Exhibit 1). However. WBS 2 was not used for this 


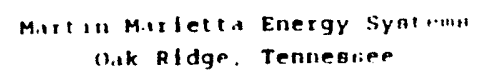

TAKE OFF EXTENSION

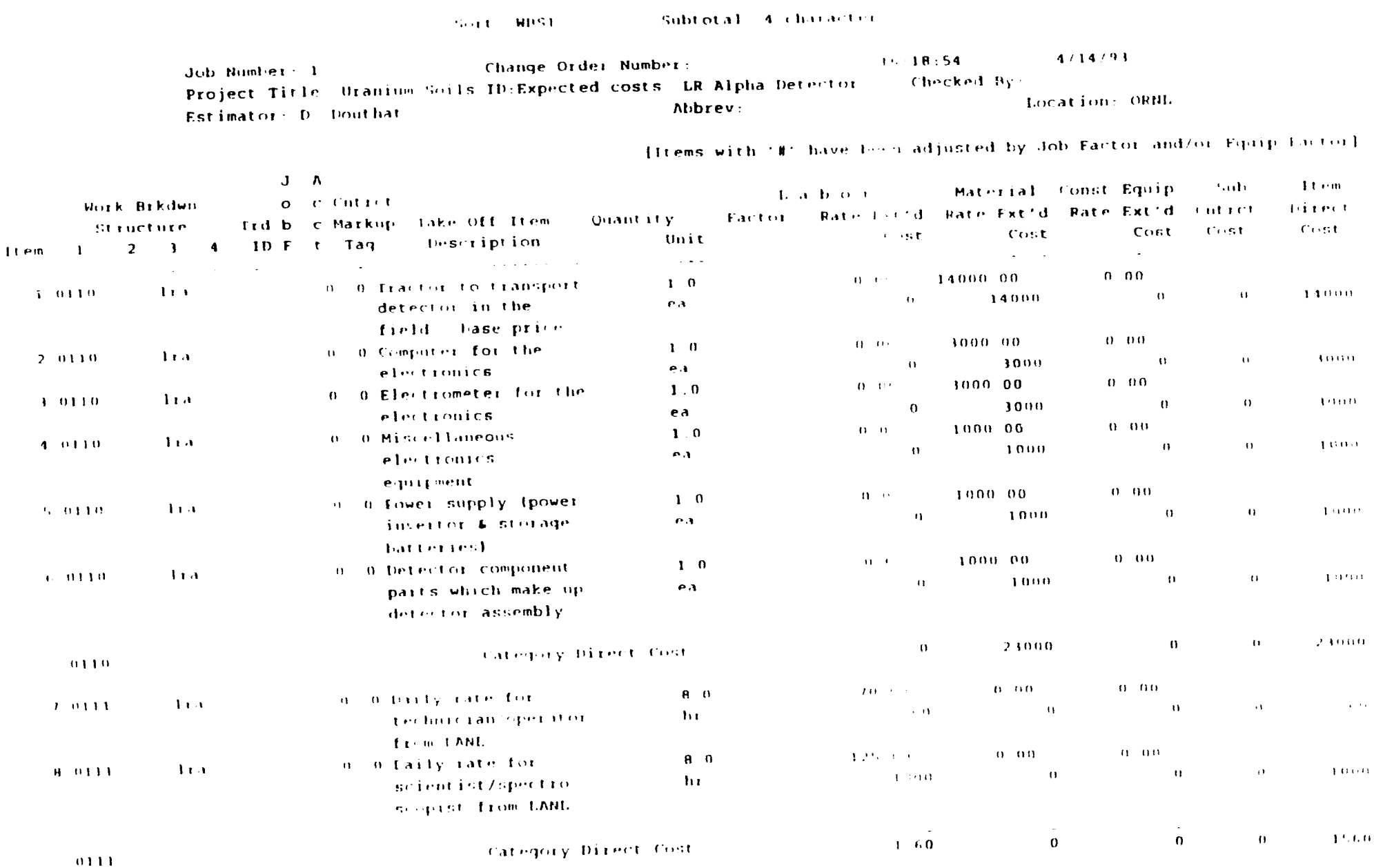

Exhibit 1. Page 1 of the long-range alpha detector take-off extension report. 


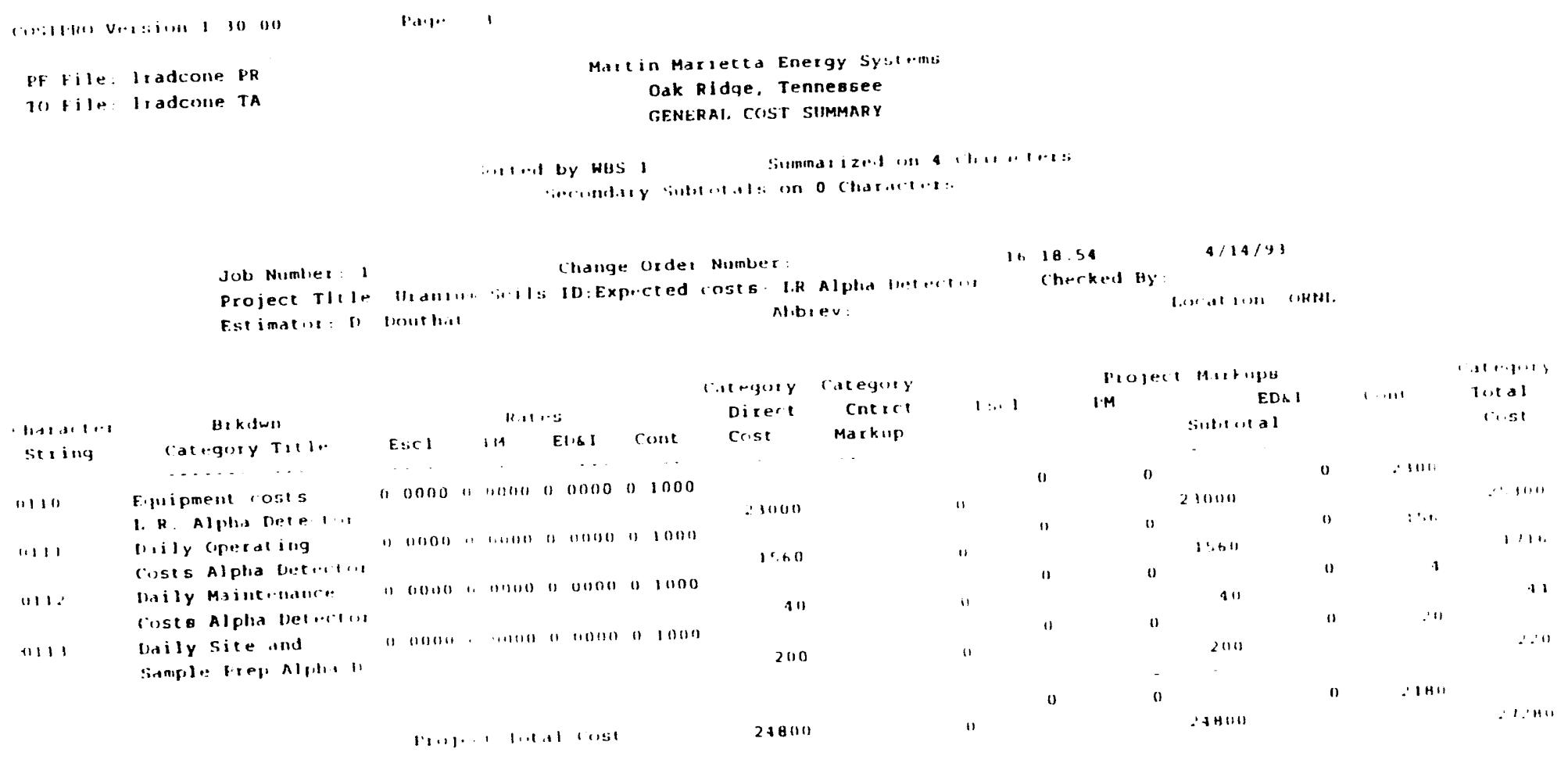

Exhibit 2. General cost summary-long-range alpha detector. 


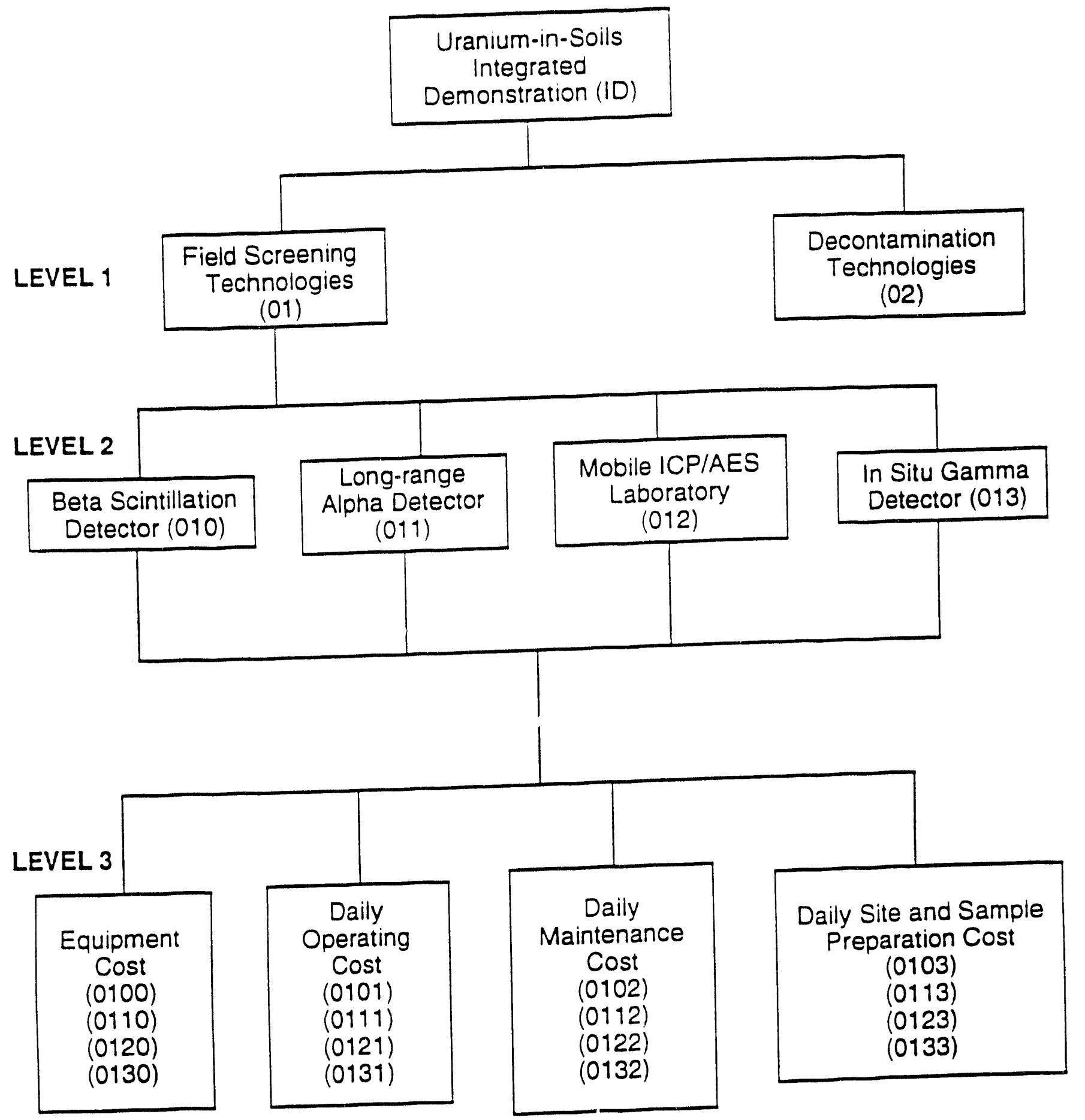

Fig. 1. WBS tree for field screening technologies. 
project because it is normally reserved for the Construction Specifications Institute (CSI). The CSI format was designed to provide a standard arrangement for specifications of estimating takeoff items for the construction industry'.

The character strings and their titles were defined by the estimator in the COSTPRO project factors file for each field screening technology and can be shown on the general cost summaries, based on the estimator's preference. Referring to the WBS tree (Fig. 1), the numerals in the character strings increase by one with each level (moving down the tree). For example, Level 1 has two characters (e.g., 01), Level 2 has three characters (e.g., 010), and Level 3 has four characters (e.g., 0100). Level 1 for the Uranium-in-Soils ID technologies is entitled "Field Screening Technologies" and is arbitrarily defined by two characters (the character string 01). This category is further broken down in Level 2 into the field screening technologies. with their associated three character string values shown in parentheses: 1) beta scintillation detector (010); 2) long-range alpha detector $(011) ; 3)$ mobile laser ablation-inductively coupled plasma/atomic emission spectrometry (LA-ICP/AES) laboratory (012); and 4) in situ gamma detector (013). Each technology was broken down by the estimator into the following four subcategories in Level 3, with their associated four-character string values shown in parentheses: 1) equipment costs $(01 \times 0$, where $\mathrm{x}$ is the value zero, one, two, or three, depending on the technology); 2$)$ daily operating costs $(01 \times 1)$; 3) daily maintenance costs (01)2); and 4) daily site and sample preparation costs $(01 \times 3)$. Therefore, as an example, equipment costs for the beta scint illation detector and long-range alpha detector were assigned character string values of 0100 and 0110 , respectively. The take-off extension report for the long-range alpha detector (Exhibit 1 ) lists the equipment costs as items 1 through 6 (which total \$23,000) in WBS 1 as character string 0110 .

\section{ASSUMPTIONS FOR THE COST ANALYSIS REPORTS}

For purposes of this report, the cost estimator attempted to keep the assumptions used in developing the cost analysis reports consistent for each field screening technology. Although the four technologies are not necessarily in competition with each other because each measures different surface areas and different forms of uranium speciation. consistency must be maintained in developing the cost analysis reports. Therefore, these assumptions are explained so the reader will understand how the cost values on the cost analysis reports were determined. 
An important assumption made by the Performance Assessment Group members is that the cost estimates should be based on the present state of the technology, not on what occurred during the field study at the Fernald site in the fall of 1992. or what is planned in the future for the field screening technologies. One advantage of COSTPRO is its ease in updating the take-off items that make up each cost estimate. Therefore. the cost analysis reports will be fairly easy to modify in the future when improvements or revisions are made to the technologies.

The operating costs. maintenance and replacement costs, and site and sample preparation costs for each field screening technology were calculated and reported as a daily rate. Labor rates for personnel to operate the equipment, which are shown as operating costs on the cost reports, are based on an 8-hour working day. This is believed to be more realistic than reporting hourly rates for operating costs because. in some cases (such as the beta scintillation detector) the scientist/spectroscopist did not have to provide 8 hours of support during a particular workday. Equipment costs for the technologies are exclusive and independent of their respective daily operating, daily maintenance and replacement, and daily site and sample preparation costs. Although it is appropriate to add the operating, maintenance and replacement, and site and sample preparation costs to get a daily rate, it is inappropriate to sum the equipment costs with these daily costs. Another assumption is that personnel at the DOE national laboratories who developed the field screening technologies would be operating the equipment, since they are familiar with the equipment and would be responsible for the work if they were asked to characterize a site.

Contingency is a project markup factor normally applied to cost estimates to account for any uncertainties or unforeseen occurrences, such as inflationary price trends, bad weather conditions, or possible material shortages associated with a project. A contingency rate of $10 \%$ was added to each category (equipment cost, daily operating cost, daily maintenance cost, and daily site and sample preparation cost) in calculating the expected costs for the field screening technologies. The Means Site Work and Landscape Cost Data, 12th Annual Edition states that contingencies are a matter of judgment and recommends using a contingency factor of $5 \%$ to $10 \%$ for calculating project costs. Because of the experimental and developmental nature of these technologies, as well as the Uranium-in-Soils ID in general, it was assumed that a $10 \%$ contingency rate would be the most appropriate for calculating the expected costs of the 
technologies. However. for the Scenario Evaluation-Cost Per Sample and Scenario Evaluation-Total Expected Cost reports for each field screening technology, a $20 \%$ contingency rate was added to the direct cos's. Based on discussions with various groups who conduct site characterizations, a $20 \%$ contingency faitor is preferable for estimates involving the characterization of a hypothetical site because of the high degree of uncertainty involved in calculating the scenario costs.

The total daily maintenance cost for each field screening technology is the sum of two cost components: 1) the expected costs to maintain the equipment and 2) the expected costs to replace the equipment component parts (e.g., detector, electronics, etc.) once they become either worn out or obsolete. Both of these cost components were reported as a daily rate. In terms of the daily maintenance costs for the technologies, many assumptions were made concerning the replacement costs for the major components of the equipment. The following explains how the value of 200 days per year was determined for the daily replacement cost of the equipment: even though there are 250 workdays in a year, the equipment will probably only be used for 10 out of 12 months of the year because of extreme weather conditions such as cold and/or rain. Converting the 250 working days in a year to days/month results in 20.83 days/month (divide by 12 ). Therefore, subtracting the two months from the total yields approximately 208 usable days/year [250 - 2(20.83)] for the equipment. Finally, assuming approximately 8 days/year down time due to maintenance of the field screening equipment results in the value of 200 usable workdays per year used in the replacement cost calculations.

The number of years of usage for the equipment was based on input from the developers of the field screening technologies and opinions from personnel experienced in using similar equipment to conduct site characterizations at similar contaminated sites. For the beta scintillation, in situ gamma, and long-range alpha detectors, the assumption was made that the actual detector components of the field screening technologies would last 5 years before replacement is necessary. Factors such as extreme temperature operating conditions, moisture, and humidity contributed to the decision that a 5-year replacement time for the detector was reasonable. Another factor was that different equipment operators. with different levels of experience, will be using the equipment, which obviously will affect the equipment's treatment during operation and storage. 
The electronic components associated with each field screening technology, such as computers. signal processors. amplifiers. and analyzers, were assumed to last 2.5 years before replacement is necessary. The assumption was made that computers used for these field screening technologies are standard equipment not originally designed to be subjected to outdoor field conditions (e.g., extreme temperature, humidity, and moisture). Therefore. computer replacement time should be shorter than that of the detector components. In addition, because of the rapidly advancing computer industry, the equipment and software presently used for each technology may need to be replaced as obsolete after 2.5 years, even if it is still operating efficiently in the field. Another assumption the Performance Assessment Group estimators made was the tractor used to maneuver the long-range alpha detector would last 10 years before needing replacement. The tractor represents a major portion of the field screening equipment's total cost; therefore, it was assumed that, with proper maintenance, the tractor should last 10 years before being upgraded or replaced. For the mobile LA-ICP/AES laboratory, the developer at Ames Laboratory estimated that the instrumentation should last 3 to 5 years before needing replacement. Therefore, the average value of 4 years was used to calculate the daily replacement cost for the instrumentation components.

Calculation of the daily replacement cost for the field screening technologies involves converting the present value of the equipment to a future value based on an assumed yearly inflation rate and the number of years the equipment is expected to last. A yearly inflation rate of $5 \%$ was used for all future value calculations. The following formula was used to calculate the future value of the equipment:

$$
F V=P V(1+i)^{n}
$$

where:

$F V=$ the future value of equipment component;

$\mathrm{PV}=$ the present value of equipment component;

$\mathrm{i} \quad=$ the yearly inflation rate; and

$\mathrm{n}=$ the number of years equipment is expected to last. 
The daily replacement cost may then be calculated by dividing the future value by the number of days the equipment is expected to remain operable. The following example for the beta scintillation detector shows how the daily replacement cost of the sensor equipment was calculated:

Referring to the take-off extension for the Uranium Soils ID: Expected Costs-Beta Scin. Detect. COSTPRO report in Appendix A, the present value of the sensor is:

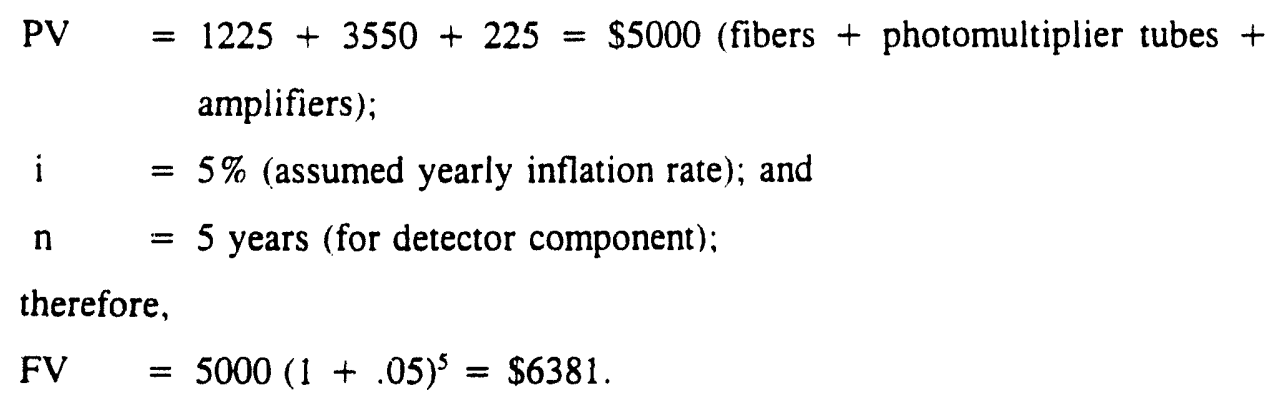

Assuming the equipment will be used 200 days/year for 5 years,

Daily Replacement Cost of Sensor $=6381 /(200 \times 5)=\$ 6.38$

\section{EXPECTED COSTS FOR THE FIELD SCREENING TECHNOLOGIES}

A summary of the expected costs for each field screening technology is provided in Table 1. A contingency rate of $10 \%$ was added to each of the four categories of costs to account for any uncertainties and unforseen occurrences associated with each of the field screening technologies. As stated earlier, the direct equipment costs shown in Table 1 are exclusive and independent of (and should not be summed with) their respective daily operating, daily maintenance and replacement, and daily site and sample preparation costs. 
Table 1. Expected costs for the field screening technologies

\begin{tabular}{|c|c|c|c|c|}
\hline \multirow{2}{*}{ PARAMETER } & \multicolumn{4}{|c|}{ FIELD SCREENING TECHNOLOGY } \\
\hline & $\begin{array}{c}\text { Beta } \\
\text { Scintillation } \\
\text { Detector }\end{array}$ & $\begin{array}{l}\text { In Situ } \\
\text { Gamma } \\
\text { Detector }\end{array}$ & $\begin{array}{l}\text { Long-Range } \\
\text { Alpha Detector }\end{array}$ & $\begin{array}{l}\text { Mobile LA- } \\
\text { ICP/AES } \\
\text { Laboratory }\end{array}$ \\
\hline $\begin{array}{l}\text { Direct Equipment } \\
\text { Costs }\end{array}$ & $\$ 15,000$ & $\$ 40.000$ & $\$ 23.000$ & $\$ 496,100$ \\
\hline Daily Operating Costs & $\$ 1040$ & $\$ 1050$ & $\$ 1560$ & $\$ 1840$ \\
\hline $\begin{array}{l}\text { Daily Maintenance and } \\
\text { Replacement Costs }\end{array}$ & $\$ 39$ & $\$ 73$ & $\$ 40$ & $\$ 442$ \\
\hline $\begin{array}{l}\text { Daily Site and Sample } \\
\text { Preparation Costs }\end{array}$ & $\$ 200$ & $\$ 0$ & $\$ 200$ & $\$ 128$ \\
\hline \multicolumn{5}{|c|}{ CONTINGENCY ADDED TO COSTS: } \\
\hline $\begin{array}{l}\text { Equipment Costs with } \\
10 \% \text { Contingency }\end{array}$ & $\$ 16,500$ & $\$ 44,000$ & $\$ 25,300$ & $\$ 545,710$ \\
\hline $\begin{array}{l}\text { Daily Operating Costs } \\
\text { with } 10 \% \text { Contingency }\end{array}$ & $\$ 1144$ & $\$ 1155$ & $\$ 1716$ & $\$ 2024$ \\
\hline $\begin{array}{l}\text { Daily Maintenance and } \\
\text { Replacement Costs } \\
\text { with } 10 \% \text { Contingency }\end{array}$ & $\$ 43$ & $\$ 80$ & $\$ 44$ & $\$ 486$ \\
\hline $\begin{array}{l}\text { Daily Site and Sample } \\
\text { Preparation Costs with } \\
10 \% \text { Contingency }\end{array}$ & $\$ 220$ & $\$ 0$ & $\$ 220$ & $\$ 141$ \\
\hline
\end{tabular}




\subsection{BETA SCINTILLATION DETECTOR}

The principal investigator for the beta scintillation detector is Alan Schilk at Pacific National Laboratory (PNL). Referring to character string 0100 on the general cost summary in Appendix A. the total direct equipment cost for the beta scintillation detector is $\$ 15.000$, which includes the cost of the component parts that make up the sensor and the external electronics of the beta detector (Table 1). A daily operating cost of $\$ 1040$, shown in character string 0101 , is made up of the PNL rates for a technician and a scientist to work 8 and 4 hours, respectively, in the field. Appropriate overhead rates have been applied to the daily personnel rates shown in the cost analysis reports for all the field screening technologies. The expected total maintenance and replacement cost is shown in character string 0102 . The maintenance cost for the beta detector is expected to be $\$ 200$ a month. Based on the assumption of 200 workdays/year and 10 months of use (200 days/10 months), there are 20 workdays during the month. Therefore, the calculated daily maintenance cost equals $\$ 10$ ( $\$ 200$ per month/20 workdays in a month). The daily replacement cost for the sensor, assuming a useful life of 5 years. is $\$ 6$. The daily replacement cost for the external electronics, assuming a useful life of 2.5 years, is $\$ 23$. Therefore, the sum of the daily maintenance cost and the replacement costs yields the total direct daily maintenance cost of $\$ 39$. The only site and sample preparation activity associated with the beta scintillation detector is trimming the grass and weeds to approximately 1 inch high. The $\$ 200$ value shown for the site and sample preparation cost in character string 0103 is based on a $\$ 25$ per hour charge rate for a site maintenance crew member to cut any vegetation during an 8-hour workday.

\subsection{IN SITU GAMM « DETECTOR}

The principal investigator for the in situ gamma detector is Alan Schilk at PNL. Referring to character string 0130 on the general cost summary in Appendix A, the total direct equipment cost for the gamma detector is $\$ 40,000$ (Table 1). This includes the cost of the high purity germanium detector, the external electronics, and the data acquisition and reduction software. The daily operating cost of $\$ 1050$, shown in character string 0131 , is made up of the PNL rates for a technician and a scientist to work 8 and 4 hours, respectively, in the field. Other daily operating costs include liquid nitrogen for the detector and gloves and a faceshield to be used while filling the liquid nitrogen reservoir. The expected total maintenance cost is expected to be the same as the beta detector ( $\$ 200$ a month). Assuming 200 days/year and 10 months of use, the calculated daily maintenance cost is $\$ 10$. The daily replacement cost for the detector. 
assuming a useful life of 5 years, is $\$ 36$. The daily replacement cost for the electronic components and sofiware, assuming a useful life of 2.5 years, is $\$ 27$. Therefore, the total direct daily maintenance cost for the gamma detector is \$73, shown in character string 0132 of the general cost summary (Appendix A). No site and sample preparation costs are associated with this technology.

\subsection{LONG-RANGE ALPHA DETECTOR}

The principal investigator for the long-range alpha detector (LRAD) is Duncan MacArthur at the LANL. Referring to character string 0110 on the general cost summary in Appendix A, the total direct equipment cost for the LRAD is $\$ 23.000$ (Table 1). This includes the cost of the detector assembly, power supply, electronics. and the tractor used to maneuver the detector assembly. The daily operating cost of $\$ 1560$. shown in character string 0111 , includes the rates for a LANL technician and scientist to each work 8 hours in the field. Daily maintenance costs are shown in character string 0112. MacArthur stated that his maintenance costs for the 2 weeks of characterization at the Fernald site in the fall of 1992 were approximately $\$ 1000$. These costs occurred because this was the first time the LRAD was field tested and included many last minute changes, such as broken wires, etc. Therefore, under normal operating conditions this value is probably high. The technology has improved since that time; therefore, MacArthur believed the maintenance costs for the LRAD should be approximately \$200 a month, the same as the beta scintillation and in situ gamma detectors. The calculated daily maintenance cost of $\$ 10$ is based on 200 days/year and 10 months of use. The daily replacement cost for the detector and power supply, assuming a useful life of 5 years, is $\$ 3$. The daily replacement cost of $\$ 16$ for the electronics is based on 2.5 years of useful life. The tractor is a major equipment expense and therefore, with proper maintenance, should have a useful life of 10 years. The tractor's daily replacement cost is $\$ 11$. Therefore, the sum of the daily maintenance cost and replacement costs for the equipment yields the total direct daily maintenance cost of $\$ 40$. The only site and sample preparation activity associated with the LRAD is trimming the grass and weeds. The $\$ 200$ value shown for the site and sample preparation cost in character string 0113 is hased on a $\$ 25$ per hour charge rate for a site maintenance crew member to cut any vegetatiun during an 8-hour workday. 


\subsection{MOBILE LA-ICP/AES LABORATORY}

The Mobile Demonstration Laboratory for Environmental Screening Technologies (MDLEST), currently demonstrating the LA-ICP/AES, is being developed by Marvin Anderson and Thomas Noble at the Ames Laboratory/lowa State University. Referring to character string 0120 on the general cost summary in Appendix A, the total direct equipment cost for the mobile LA-ICP/AES Laboratory is $\$ 496,100$ (Table 1). The equipment costs are broken down into three major areas: 1) instrumentation and automation, 2) the utilities to house and operate the equipment, and 3) safety equipment and training. The instrumentation and automation includes the AES, ICP, NdYag laser, laser rastering system, laser focusing and optics, microwave dissolution system, four computers (three 386s and one 486), an ink jet printer, multicolor plotter, computer software, and an optical disk and drive. The utilities to house and operate the equipment include a 44- $\mathrm{ft}$. fifth-wheel trailer, diesel truck, diesel generator, 1.5 horsepower water chiller, robotic accessory trailer, radio communications system, closed circuit television system, cellular telephone, and automatic valves and sensors. Safety equipment and training includes a commercial driver's license, Occupational Safety and Health Administration (OSHA) Hazardous Operations Waste Training, laser eye protection, window curtains, a hazardous gas detector, and a radio activity counter.

The daily operating costs (character string 0121) for this technology total $\$ 1840$. The personnel rate of $\$ 200$ per hour is based on four properly trained Ames technicians ( $\$ 50$ /hour, including overhead) working in the mobile laboratory and the field. At the Fernald characterization demonstration conducted in the fall of 1992. Anderson stated that the hourly charge rate for personnel was $\$ 600$. However, this figure reflects the salaries of more than four personnel and does not represent improvements to the mobile laboratory system implemented since the demonstration, which have helped lower the personnel rate to $\$ 200$ per hour. Once the

mobile laboratory is set up at the site, the hourly cost for operation is $\$ 30$, resulting in a daily rate of $\$ 240$. This includes generator fuel, truck fuel, instrumentation gases, cellular phone use, standard samples, and minor repair and maintenance costs for instrumentation, utility systems, and the truck and trailer.

The daily maintenance and replacement costs for the mobile ICP/AES laboratory are shown in character string 0122. Major repairs that require a manufacturer's representative should be 
infrequent, and the cost for parts and labor was estimated at $\$ 10.000$ per year. However, it should be noted that the current technology in the MDLEST, the LA-ICP/AES, has not needed any major repairs. so this is just an estimate. Assuming this equipment is used 200 days per year, the daily maintenance cost would be $\$ 50$ ( $\$ 10.000 / 200)$. The daily replacement cost for the instrumentation, assuming a useful life of 4 years. is $\$ 392$. This value is based on a present value of $\$ 257,700$ for the instrumentation components. Therefore, the total direct daily maintenance cost for the mobile ICP/AES laboratory is $\$ 442(\$ 50+\$ 392)$.

For site and sample preparation costs, a 12 in. $\times 12$ in. sampling site is scraped bare of all vegetation, and large rocks are removed. The estimated cost for this effort is $\$ 16$ per hour or approximately $\$ 4$ per sampling site times the number of sampling sites, resulting in a daily rate of $\$ 128$.

\section{SCENARIO EVALUATIONS FOR THE FIELD SCREENING TECHNOLOGIES}

A scenario evaluation was included in the cost input questionnaires sent to the developers of the field screening technologies to determine the cost to adequately characterize a hypothetical 1 -acre site in a given timeframe. The hypothetical site was used as a storage area for uraniumcontaminated scrap metal and drums containing mill tailings. Five years ago, the material and drums were removed, no remedial action was conducted, and the site was abandoned. The developers of the four technologies were given a maximum of 24 hours (three 8-hour working days) for sampling and other activities believed necessary to adequately characterize the site using their field screening technology. It is important to note that each developer was responsible for determining the number of samples taken (Tables 2 and 3 ) and the extent of sampling necessary to create an "adequate" characterization of the hypothetical site.

Two cost analysis reports were created for each technology based on responses to the scenario evaluation in the cost input questionnaire. The report, Scenario Evaluation-Cost per Sample, includes the costs associated with adequately characterizing the hypothetical site once the crew is set up and ready to begin characterizing the site. This estimate excludes all transportation. 
lodging, and per diem costs for the crews operating the technology. The cost estimate reflects the minimum time that personnel need to be in the field while characterizing the site.

The second scenario cost analysis report. Scenario Evaluation-Total Expected Cost. includes the total costs to characterize the hypothetical site if an interested party asked each of the developers of the field screening technologies to provide a bid for site characterization. This report reflects a more realistic cost estimate than its counterpart: the Scenario Evaluation-Cost Per Sample report. The Total Expected Cost report includes the total cost to characterize the site from start to finish, or, in other words, from the time the technology developers leave their facility for the hypothetical site until they complete the characterization and return to their original destination. Therefore, travel costs and personnel salaries for the travel days to and from the site were included in the cost estimates. In addition, the labor cost for the additional hours personnel are required to be on the site were included in the Total Expected Cost scenario evaluation reports. For example, the technology developer stated that the PNL scientist using the beta scintillation detector is required to be in the field for only 4 hours during the 3 days of characterization (one day for establishing the sampling grid plus 2 days of sampling) (See Scenario Evaluation-Cost Per Sample-Beta Det. COSTPRO report in Appendix A). However, the scientist still has to be on the site while the sampling grid is being established, as well as during the 2 days of sampling. Therefore, an additional 36 hours ( 16 hours for travel plus 20 hours during the 3 days of characterization) of the scientist's labor costs were included in the Scenario Evaluation-Total Expected Cost-Beta COSTPRO report for the beta scintillation detector.

\subsection{BETA SCINTILLATION DETECTOR}

The developer of the beta scintillation detector reported that it would take 3 days to adequately characterize the hypothetical 1-acre site in the scenario evaluation. A PNL technician requires one day to establish a sampling grid and locate approximately 100 evenly spaced sample locations. The remaining 2 days would be devoted to sampling the site, including 16 hours for a PNL technician to collect the samples (including physically moving the sensor) and 4 hours for data reduction requirements by the PNL scientist. Referring to the Scenario Evaluation-Cost Per Sample-Beta Det. report in Appendix A, the minimum total direct cost (excluding travel and associated personnel costs shown in the total expected cost report) for characterizing the site is 
$\$ 2438$, or $\$ 24.38$ per sample (2438/100). Adding a 20\% contingency rate for any uncertainties associated with the project results in a total cost of \$2926. or \$29.26 per sample (2926/100). A summary of the Scenario Evaluation-Cost Per Sample report for each field screening technology is provided in Table 2.

The Scenario Evaluation-Total Expected Cost-Beta COSTPRO report includes 2 days of

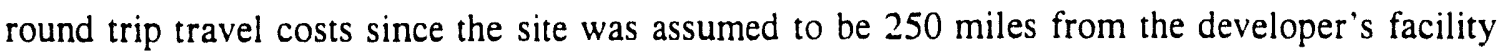
location. These travel costs include lodging for 4 nights, per diem for 5 lays, and transportation in a company van for the two-member crew needed to operate the technology. In addition, 2 days (16 hours) at the PNL technician labor rate were included for the required travel days. Thirty-six hours of labor time for the PNL scientist were also included in the cost estimate because of the 2 travel days ( 16 hours) and the additional time ( 20 hours) that the scientist is on the site while the sampling grid is being established and during sampling. Referring to the Scenario Evaluation-Total Expected Cost-Beta report in Appendix A, the total direct cost to characterize the hypothetical 1-acre site for this scenario is $\$ 8898$, or $\$ 88.98$ per sample $(8898 / 100)$. Applying a contingency rate of $20 \%$ to this figure results in a total cost of $\$ 10,678$, or $\$ 106.78$ per sample $(10,678 / 100)$. A summary of the Scenario Evaluation-Total Expected Cost report for each fieid screening technology is provided in Table 3.

\subsection{IN SITU GAMMA DETECTOR}

The developer of the in situ gamma detector reported that it would take 2 days to adequately characterize the hypothetical 1-acre site in the scenario evaluation. A PNL technician requires one day to establish a sampling grid and locate approximately 20 evenly spaced sample locations. The technology developer stated that only one day of sampling was required to provide an adequate sampling of the site. During this one day of sampling, 3 hours are required for the PNL technician to collect the 20 samples and 2 hours are required for the PNL scientist to provide the data reduction. Referring to the Scenario Evaluation-Cost Per Sample-Gamma Det. report in Appenciix A, the minimum total direct cost (excluding travel and associated personnel costs, etc.) for characterizing the site is $\$ 1083$. or $\$ 54.15$ per sample $(1083 / 20)$. Adding a $20 \%$ contingency rate for any uncertainties associated with the project results in a total project cost of $\$ 1300$, or $\$ 65.00$ per sample (1300/20) (Table 2). 
Table 2. Scenario evaluation-cost per sample

\begin{tabular}{||l|c|c|c|c||}
\hline \multirow{2}{*}{ PARAMETER } & \multicolumn{3}{|c|}{ CHARACTERI/ATION TECHNOLOGY } \\
\cline { 2 - 5 } & $\begin{array}{c}\text { Beta } \\
\text { Scintillation } \\
\text { Detector }\end{array}$ & $\begin{array}{c}\text { In Situ Gamma } \\
\text { Detector }\end{array}$ & $\begin{array}{c}\text { Long-Range } \\
\text { Alpha Detector }\end{array}$ & $\begin{array}{c}\text { Mobile LA- } \\
\text { ICP/AES } \\
\text { Laboratory }\end{array}$ \\
\hline $\begin{array}{l}\text { Number of } \\
\text { samples taken }\end{array}$ & 100 & 20 & 100 & 44 \\
\hline $\begin{array}{l}\text { Direct cost to } \\
\text { characterize 1- } \\
\text { acre site }\end{array}$ & $\$ 2438$ & $\$ 1083$ & $\$ 5560$ & $\$ 10,225$ \\
\hline Cost per sample & $\$ 24.38$ & $\$ \mathbf{5 4 . 1 5}$ & $\mathbf{\$ 5 5 . 6 0}$ & $\$ \mathbf{2 3 2 . 3 9}$ \\
\hline $\begin{array}{l}\text { Cost to } \\
\text { characterize 1- } \\
\text { acre site with } \\
\text { 20\% contingency }\end{array}$ & $\$ 2926$ & $\$ 1300$ & $\$ 6672$ & $\$ 12,270$ \\
\hline $\begin{array}{l}\text { Cost per } \\
\text { sample, } \\
\text { including 20\% } \\
\text { contingency }\end{array}$ & $\$ \mathbf{2 9 . 2 6}$ & $\mathbf{\$ 6 5 . 0 0}$ & $\mathbf{\$ 6 6 . 7 2}$ & $\$ \mathbf{2 7 8 . 8 6}$ \\
\hline
\end{tabular}

Note: The values shown for each screening technology are from the cost analysis reports, entitled Scenario Evaluation-Cost Per Sample, for each technology. This scenario represents the costs associated with adequately characterizing the hypothetical 1 -acre site once the crew is setup and ready to begin characterization. These estimates exclude all transportation, lodging, and per diem costs for the crews operating the characterization technologies. In addition. these cost estimates reflect the minimum time that personnel need to be in the field while characterizing the site. 
Table 3. Scenario evaluation-total expected cost

\begin{tabular}{|c|c|c|c|c|}
\hline \multirow{2}{*}{ PARAMETER } & \multicolumn{4}{|c|}{ CHARACTERIZATION TECHNOLOGY } \\
\hline & $\begin{array}{c}\text { Beta } \\
\text { Scintillation } \\
\text { Detector }\end{array}$ & $\begin{array}{l}\text { In Situ Gamma } \\
\text { Detector }\end{array}$ & $\begin{array}{l}\text { Long-Range } \\
\text { Alpha Detector }\end{array}$ & $\begin{array}{l}\text { Mobile LA- } \\
\text { ICP/AES } \\
\text { Laboratory }\end{array}$ \\
\hline $\begin{array}{l}\text { Number of } \\
\text { samples taken }\end{array}$ & 100 & 20 & 100 & 44 \\
\hline $\begin{array}{l}\text { Direct cost to } \\
\text { characterize } 1- \\
\text { acre site }\end{array}$ & $\$ 8898$ & $\$ 6973$ & $\$ 12,900$ & $\$ 15,465$ \\
\hline Cost per sample & $\$ 88.98$ & $\$ 348.65$ & $\$ 129.00$ & $\$ 351.48$ \\
\hline $\begin{array}{l}\text { Cost to } \\
\text { characterize } 1 \text { - } \\
\text { acre site with } \\
20 \% \text { contingency }\end{array}$ & $\$ 10,678$ & $\$ 8368$ & $\$ 15.480$ & $\$ 18,558$ \\
\hline $\begin{array}{l}\text { Cost per } \\
\text { sample, } \\
\text { including } 20 \% \\
\text { contingency }\end{array}$ & $\$ 106.78$ & $\$ 418.40$ & $\$ 154.80$ & $\$ 421.77$ \\
\hline
\end{tabular}

Note: The values shown for each screening technology are from the individual cost analysis reports, entitled Scenario Evaluation-Total Expected Cost, for each technology. This scenario represents the total cost to characterize the hypothetical 1 -acre site from start to finish, or in other words, from the time the technology developers leave their plant for the site until they complete the characterization and return to their original destination. Therefore, travel costs and personnel salaries while on travel would be included, as well as the labor cost for the additional hours personnel are required to be on the site. 
The Scenario Evaluation-Total Expected Cost-Gamma COSTPRO report includes 2 days of round trip travel costs since the site was assumed to be 250 miles from the developer's facility location. These travel costs include lodging for 3 nights, per diem for 4 days, and transportation in a company van for the two-member crew needed to operate the technology. Twenty-one hours of labor time for the PNL technician were included in the cost estimate because of the 2 days of travel (16 hours) and the additional 5 hours he or she is on the site during the day of sampling. Additionally, 30 hours of labor time for the PNL scientist were included because of the 2 travel days ( 16 hours) and the additional 14 hours he or she is on the site while the sampling grid is being set up and during sampling. Referring to the Scenario Evaluation-Total Expected Cost-Gamma report in Appendix A, the total direct cost to characterize the hypothetical 1-acre site for this scenario is $\$ 6973$, or $\$ 348.65$ per sample $(6973 / 20)$. Applying a contingency rate of $20 \%$ to this figure results in a total project cost of $\$ 8368$, or $\$ 418.40$ per sample $(8368 / 20)$ (Table 3).

\subsection{LONG-RANGE ALPHA DETECTOR}

The developer of the long-range alpha detector reported that it would take 4 days to adequately characterize the hypothetical 1 -acre site in the scenario evaluation-one day to establish the sampling grid and locate sample sites and 3 days to sample the site. An LANL technician requires one day to set up the sampling grid and locate approximately 100 sample locations. During the 3 days of sampling, the technician would drive the tractor and move the detector equipment, and the LANL scientist would collect readings, record the data, and plot these data at the end of each sampling day. Referring to the Scenario Evaluation-Cost Per Sample $-L R A D$ report in Appendix A, the minimum total direct cost (excluding travel and associated personnel costs, etc.) for characterizing the site is $\$ 5560$, or $\$ 55.60$ per sample $(5560 / 100)$. Adding a $20 \%$ contingency rate for any uncertainties results in a total cost of $\$ 6672$, or $\$ 66.72$ per sample $(6672 / 100)$ (Table 2$)$.

As with the scenario evaluations for the other technologies, the Scenario Evaluation-Total Expected Cost-LRAD report includes 2 days of round trip travel costs for the two-member LANL crew needed to operate the technology. These travel costs include lodging for 5 nights. per diem for 6 days, and transportation in a rental vehicle large enough to house the equipment (a U-Haul was used to transport the equipment to the Fernald site for the characterization study 
in the fall of 1992). Two days (16 hours) of labor time for the LANL technician were included because of the required travel days. In addition, 24 hours of labor time for the LANL scientist were included in the cost estimate because of the 2 travel days (16 hours) and the additional 8 hours he or she is on the site while the sampling grid is being established. Referring to the Scenario Evaluation-Total Expected Cost-LRAD report in Appendix A, the total direct cost to characterize the hypothetical 1-acre site for this scenario is $\$ 12,900$, or $\$ 129.00$ per sample $(12,900 / 100)$. Applying a contingency rate of $20 \%$ to cover iny uncertainties results in a total project cost of $\$ 15,480$, or $\$ 154.80$ per sample $(15,480 / 100)$ (Table 3 ).

\subsection{MOBILE LA-ICP/AES LABORATORY}

The developer of the MDLEST LA-ICP/AES reported that it would take 3 days to adequately characterize the hypothetical 1-acre site in the scenario evaluation. The item one direct cost of $\$ 13,200$ shown on both COSTPRO scenario evaluation cost estimates includes: 1) salaries for the 4 personnel required to operate this technology for 5 days ( 3 days of field work and 2 travel days) and 2) laboratory and equipment arnortization. Field work involves first developing a grid of $12 \mathrm{~m} \times 12 \mathrm{~m}$ squares on the 1-acre site. Forty-four samples are then collected and analyzed in the mobile laboratory during the 3-day period. Referring to the Scenario Evaluation-Cost Per Sample-LA-ICP/AES report, 64 hours for the four technicians' 2 days of travel (2 days $\mathrm{x}$ 8 hours $\times 4$ personnel) were subtracted from the cost estimate because travel costs were not included in any of the Cost Per Sample reports. The technology developer stated that the labor rate for a properly trained Ames technician was $\$ 50$ per hour (including overhead). The total maintenance costs were used in the scenario evaluations for the other three field screening technologies. The total maintenance costs include the replacement costs for the equipment plus the daily maintenance costs to operate the equipment. However, for the MDLEST LA-ICP/AES technology, only the daily maintenance cost of $\$ 50$ is included in the scenario cost estimates because the replacement cost for the instrument is covered under the laboratory amortization cost in item one of the scenario evaluations. Referring to the Scenario Evaluation-Cost Per Sample-LA-ICP/AES report in Appendix A, the minimum total direct cost (excluding travel and associated personnel costs, etc.) for characterizing the site is $\$ 10,225$, or $\$ 232.39$ per sample $(10.225 / 44)$. Adding a $20 \%$ contingency rate for any uncertainties associated with the project results in a total cost of $\$ 12,270$, or $\$ 278.86$ per sample $(12,270 / 44)$ (Table 2). 
The Scenario Evaluation-Total Expected Cost-LA-ICP/AES COSTPRO report includes 2 days of round trip travel costs for the four-member Ames Laboratory crew needed to operate the technology. The labor cost for the four personnel during the 2 days of travel is included in the item one cost of $\$ 13.200$. Other travel costs include lodging for 4 nights, per diem for 5 days, and transportation for the four Ames personnel. Two Ames technicians can travel in the diesel truck that pulls the fifth-wheel mobile laboratory and the other two personnel can use a company truck or van to travel to the site. Referring to the Scenario Evaluation-Total Expected Cost-LA-ICP/AES report in Appendix A, the total direct cost to characterize the hypothetical 1acre site for this scenario is $\$ 15,465$, or $\$ 351.48$ per sample $(15,465 / 44)$. Applying a $20 \%$ contingency rate for any uncertainties associated with the project results in a total cost of $\$ 18,558$, or $\$ 421.77$ per sample $(18,558 / 44)$ (Table 3$)$.

\section{SUMMARY}

This document describes the methodology used to develop the cost analysis reports for the uranium field screening technologies demonstrated in the fall of 1992 at the Fernald site for the Uranium-in-Soils ID. This work was conducted by Performance Assessment Group members at ORNL in support of TTP AL231007, "Cost/Risk Performance Assessment of Soil Characterization." Cost input questionnaires were developed and sent to the developers of the field screening technologies. After review of the questionnaires and verbal communication with each technology developer, cost estimates were developed for each technology. These estimates are subject to updates and revisions in the future as development of the field screening technologies continues for the Uranium-in-Soils ID.

COSTPRO, a commercial rewrite of the LANL's cost estimating system. was the computer software package used to create the cost estimates. Three cost analysis reports were created for each technology. The first report shows the technologies' expected costs, including its total direct equipment cost, daily operating cost, daily maintenance cost, and daily site and sample preparation cost. The other two reports were created based on the information gathered from a scenario evaluation included in the cost input questionnaire. The technology developers were given 24 hours (three 8 -hour working days) to adequately characterize the hypothetical 1-acre uranium-contaminated site. which is located 250 miles away from the developers facility. Each 
developer was responsible for determining the extent of sampling necessary and the number of samples taken to create an "adequate" characterization of the hypothetical site. The report. Scenario Evaluation-Cost Per Sample. includes the cost to characterize the site once the crew is setup and ready to begin characterization. This estimate excludes all transportation, lodging, and per diem costs for the crews operating the technology, and it reflects the minimum time that personnel need to be in the field while characterizing the site. The second report created from the scenario evaluation, Scenario Evaluation-Total Expected Cost, includes the total costs to characterize the hypothetical site from start to finish, or in other words, from the time the technology developers leave their facility for the hypothetical site until they complete the characterization and return to their original destination. The cost estimate includes travel, lodging, and per diem costs, as well as labor costs for personnel while they are travelling and the additional hours the personnel are required to be in the field.

The following expected costs for the beta scintillation detector, as well as the expected costs for the other three technologies, include a $10 \%$ contingency rate for any uncertainties or unforeseen occurrences associated with this technology:

$\begin{array}{ll}\text { Direct Equipment Cost }= & \$ 16,500 \\ \text { Daily Operating Cost }= & \$ 1144 \\ \begin{array}{l}\text { Daily Maintenance Cost } \\ \text { (includes maintenance and } \\ \text { future value replacement } \\ \text { costs) }\end{array} & \$ \$ 43 \\ \begin{array}{l}\text { Daily Site and Sample } \\ \text { Preparation Cost }=\end{array} & \$ 220\end{array}$

The scenario evaluation cost estimate for the beta detector, as well as the scenario cost estimates for the other three technologies, includes a $20 \%$ contingency rate for any uncertainty associated with the scenario:

Scenario Evaluation-Cost Per Sample:

Total Cost to Characterize 1-acre Site $=\$ 2926$

Cost Per Sample (100 samples taken) $=\$ 29.26$ 
Beta Scintillation Detector costs (continued):

Scenario Evaluation-Total Expected Cost:

Total Cost to Characterize 1-acre Site $=\$ 10.678$ Cost Per Sample $(100$ samples taken $)=\$ 106.78$

The following costs are for the in situ gamma detector:

$\begin{array}{lll}\text { Direct Equipment Cost } & = & \$ 44,000 \\ \text { Daily Operating Cost } & = & \$ 1155 \\ \text { Daily Maintenance Cost } & = & \$ 80 \\ \begin{array}{l}\text { Daily Site and Sample } \\ \text { Preparation Cost }\end{array} & =\$ 0\end{array}$

Scenario Evaluation-Cost Per Sample:

Total Cost to Characterize 1-acre Site $=\$ 1300$

Cost Per Sample (20 samples taken) $=\$ 65.00$

Scenario Evaluation-Total Expected Cost:

Total Cost to Characterize 1-acre Site $=\$ \$ 8368$ Cost Per Sample (20 samples taken) $=\$ 418.40$

The following costs are for the long-range alpha detector:

$\begin{array}{lll}\text { Direct Equipment Cost } & = & \$ 25.300 \\ \text { Daily Operating Cost } & = & \$ 1716 \\ \text { Daily Maintenance Cost } & = & \$ 44 \\ \begin{array}{l}\text { Daily Site and Sample } \\ \text { Preparation Cost }\end{array} & = & \$ 220\end{array}$

Scenario Evaluation-Cost Per Sample:

Total Cost to Characterize 1-acre Site $=\$ 6672$ Cost Per Sample (100 samples taken) $=\$ 66.72$ 
Long-Range Alpha Detector costs (continued):

Scenario Evaluation-Total Expected Cost:

Total Cost to Characterize 1-acre Site $=\$ 15.480$

Cost Per Sample (100 samples taken) $=\$ 154.80$

The following costs are for the mobile LA-ICP/AES laboratory:

Direct Equipment Cost

Daily Operating Cost

$=\$ 545.710$

Daily Maintenance Cost

$=\$ 2024$

Daily Site and Jample

Preparation Cost

$=\$ 486$

$=\$ 141$

Scenario Evaluation-Cost Per Sample:

Total Cost to Characterize 1-acre Site $=\$ 12,270$

Cost Per Sample (44 samples taken) $=\$ 278.86$

Scenario Evaluation-Total Expected Cost:

Total Cost to Characterize 1-acre Site $=\$ 18,558$

Cost Per Sample (44 samples taken) = \$421.77 
APPENDIX A

COST ANALYSIS REPORTS FOR THE FIELD

SCREENING TECHNOLOGIES 
PF File: Iradcone.PR TO F1le: Iradcone.TA
Martin Marletta Energy Systems

Oak R1dge, Teanessee

Sort: WBS1 Subtotal: 4 characters

Job Number: 1

Change Order Number:

Profect Title: Uranium So1ls ID: Bxpected costB- LR Alpha Detector

Est1mator: D. Douthat

Abbrev:

$14: 58: 45$

Checked By:

$11 / 4 / 93$

Location: ORNI

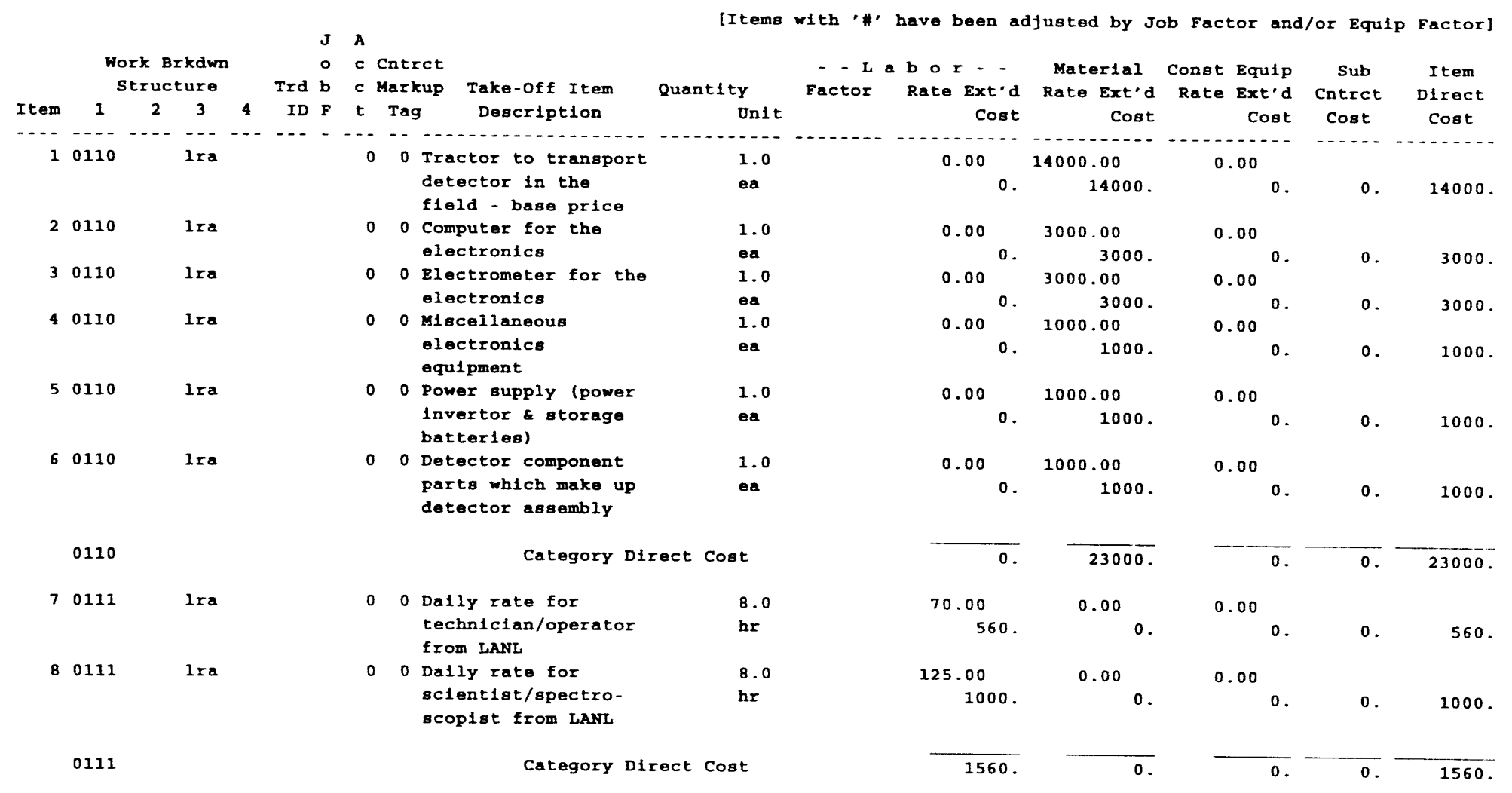




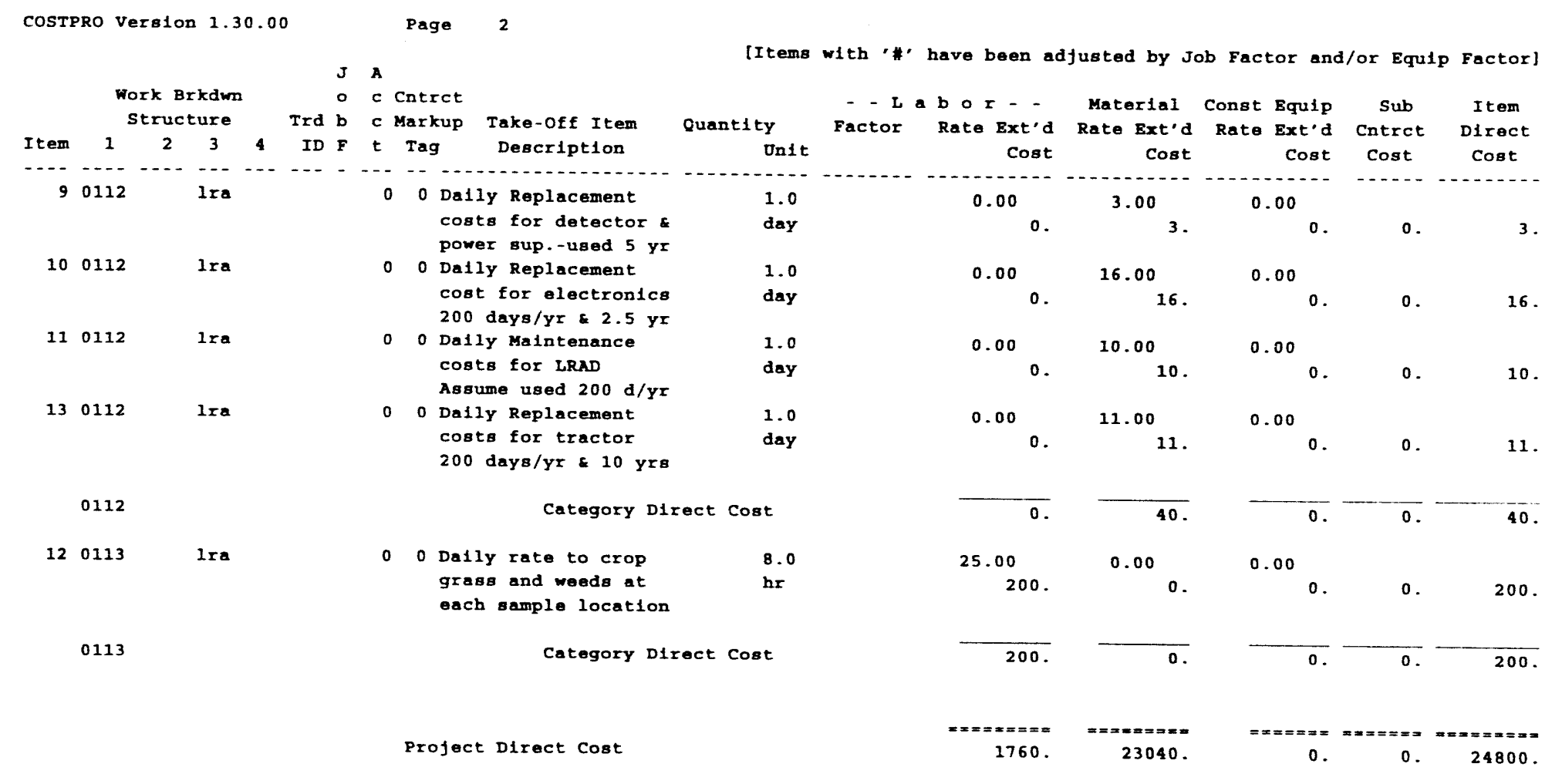


Martin Marietta Energy Systems Oak Ridge, Tennessee

Sorted by WBS 1

Summarlzed on 4 characters

secondary Subtotals on 0 Characters

Job Number: 1 Change Order Number:

Profect Title: Uranium Solls ID:Bxpected costs - LR Alpha Detector

$14: 58: 45$

Checked By

$11 / 4 / 93$

Estimator: D. Douthat Abbrev:

Location: ORND

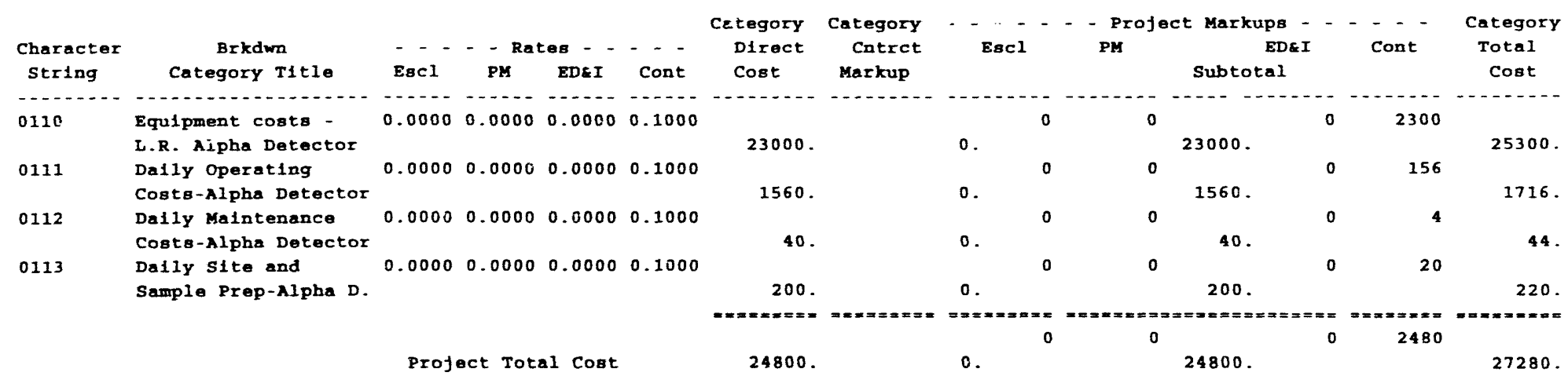


PF File: scencsad.PR TO File: scencsad. TA

Martin Marietta Energy Systems

Oak Ridge, Tennessee

\section{TAKE-OFF EXTENSION}

Job Number: 1 Change Order Number:

Profect Title: Scenario Evaluation - Cost Per Sample - LRAD

Estimator: D. Douthat

15: $5: 41$
Checked $B y:$

$11 / 4 / 93$

abbrev:

Location: ORNL

[Items with ' have been adfusted by Job Factor and/or Equip Factor

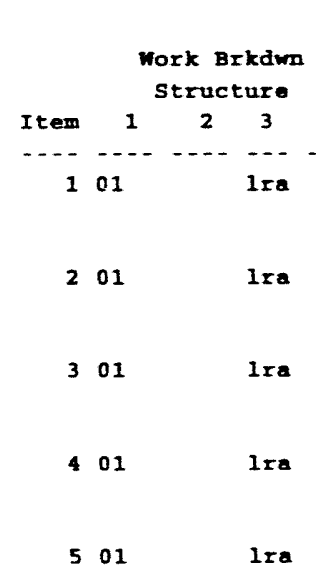

01 $\begin{array}{ll}\text { J } & \mathbf{A} \\ \circ & \text { c contrct }\end{array}$ Trd b $c$ Markup
ID $F \quad t$ Tag

Take-Off Item Quantity - I a b o r - -

0 o Crop grass and weeds 8.0 to 1 lnch high for the 1 -acre site

hr

Establiah anting

8.0 grid a locate sample sites

o O Cost for technician to drive tractor :

hr

hr

24.0 move detector-3 days hr o Cost for scientistdata reduction $₹ 100$ samples taken-3 day

- O Maintenance costs associated with LRAD 24.0
$h x$ vsed 3 days

3.0
day

day

Category Direct Cost
Material Conat Equip Sub Item Rate Ext'd Rate Ext'd Rate Ext'd Cntret Direct Cost Cost Cost Cost Cost

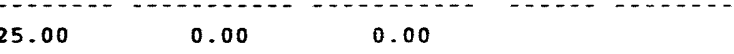
200. 0.0 .200$. $\begin{array}{ccccc}70.00 & 0.00 & 0.00 & & \\ 560 . & 0 . & 0 . & 0 . & 560\end{array}$ $\begin{array}{ccccc}70.00 & 0.00 & 0.00 & & \\ 1680 & 0 . & 0 . & 0 . & 1680\end{array}$ 125.00 3000 0.00 0.00

0.00

40.00 120. 0.00

o. 3000

$0 . \quad 0 . \quad 120$.

$5440 . \quad 50.00 .5560$. 
PF File: scencsad. PR

To F1le: scencsad.TA
Martin Marietta Energy Systems Oak Ridge, Tennessee

Sorted by WBS 1

Summarlzed on 2 characters

secondary Subtotals on O Characters

Job Number: 1

Change Order Number:

Profect Titlo: Scenario Evaluation - Cost Per Sample - LRAD Estimator: D. Douthat

Abbrev:

15: $5: 41$ Checked By

$11 / 4 / 93$

Location: ORNI

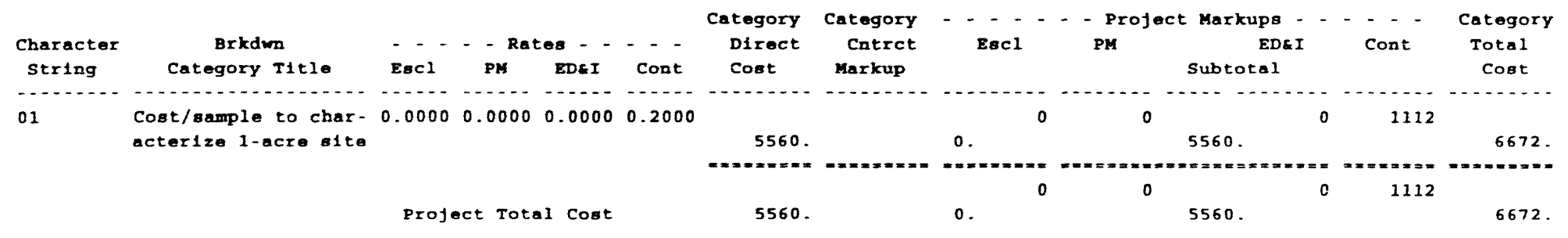




\section{PF File: scenlrad.PR}

TO File: scenlrad.TA
Martin Marletta Energy Systems

Oak RIdge. Tennessee

\section{TAKB-OFF EXTENSION}

Sort: WBS1 Subtotal: 2 characters

Job Number: 1 Change Order Number:

$15: 11: 25$

$11 / 4 / 93$

Project Title: Scenar

Abbrev:

Location: ORN

\begin{tabular}{|c|c|c|c|c|c|c|c|c|c|c|c|c|c|c|c|c|}
\hline Item & 1 & $\begin{array}{r}\text { Work } \\
\text { Struc } \\
2\end{array}$ & $\begin{array}{l}\text { ikdwn } \\
3\end{array}$ & 4 & $\begin{aligned} & J \\
& 0 \\
\text { Trd } & b \\
\text { ID } & F\end{aligned}$ & $\begin{array}{l}\text { A } \\
c \quad c \\
c \\
t\end{array}$ & $\begin{array}{l}\text { Cntr } \\
\text { Mark } \\
\text { Tag }\end{array}$ & $\begin{array}{c}\text { ct } \\
\text { cup } \\
\text { Desc-off Item } \\
\text { Desciption }\end{array}$ & $\begin{array}{l}\text { Quant1ty } \\
\text { Unit }\end{array}$ & $\begin{array}{c}\text { wth ' } \\
-\quad \mathrm{L} \\
\text { Factor }\end{array}$ & $\begin{array}{l}\text { have been ad } \\
\text { b o }=- \\
\text { Rate Ext'd } \\
\text { Cost }\end{array}$ & $\begin{array}{l}\text { Justed by Jo } \\
\text { Material } \\
\text { Rate Ext'd } \\
\text { Cost }\end{array}$ & $\begin{array}{l}\text { ab Fact } \\
\text { Const } \\
\text { Rate }\end{array}$ & $\begin{array}{l}\text { tor an } \\
\text { Equip } \\
\text { Ext'd } \\
\text { Cost }\end{array}$ & $\begin{array}{l}\text { 1/or Equip } \\
\text { Sub } \\
\text { Cntrct } \\
\text { Cost }\end{array}$ & $\begin{array}{l}\text { Factor] } \\
\text { Item } \\
\text { Direct } \\
\text { Cost }\end{array}$ \\
\hline 1 & 01 & & lra & & & 0 & 0 & $\begin{array}{l}\text { Crop grass and weeds } \\
\text { to } 1 \text { inch high for } \\
\text { the I-acre site }\end{array}$ & $\begin{array}{l}8.0 \\
\mathrm{hr}\end{array}$ & & $\begin{array}{r}25.00 \\
200 .\end{array}$ & 0.00 & & 0.00 & 0. & 200. \\
\hline 2 & 01 & & $1 \times 8$ & & & 0 & 0 & $\begin{array}{l}\text { Establish sampling } \\
\text { grid f locate sample } \\
\text { sttes }\end{array}$ & $\begin{array}{l}8.0 \\
\mathrm{hr}\end{array}$ & & $\begin{array}{l}70.00 \\
560 .\end{array}$ & $\begin{array}{l}0.00 \\
0 .\end{array}$ & & $\begin{array}{l}0.00 \\
0 .\end{array}$ & 0. & 560. \\
\hline 3 & 01 & & lra & & & 0 & 0 & $\begin{array}{l}\text { Cost for technician } \\
\text { to drive tractor } \\
\text { move detector-3 days }\end{array}$ & $\begin{array}{c}24.0 \\
\mathrm{hr}\end{array}$ & & $\begin{array}{l}70.00 \\
1680 .\end{array}$ & $\begin{array}{l}0.00 \\
0 .\end{array}$ & & $\begin{array}{l}0.00 \\
0 .\end{array}$ & 0. & 1680. \\
\hline 4 & 01 & & $1 \times a$ & & & 0 & $\begin{array}{rl}0 & 0 \\
0 & 0 \\
0 & 0\end{array}$ & $\begin{array}{l}\text { Cost for sclent1st- } \\
\text { data reduction a } 100 \\
\text { samples taken-3 days }\end{array}$ & $\begin{array}{c}24.0 \\
\mathrm{hr}\end{array}$ & & $\begin{array}{l}125.00 \\
3000\end{array}$ & $\begin{array}{l}0.00 \\
0 .\end{array}$ & & 0.000. & 0. & 3000. \\
\hline 5 & 01 & & 150 & & & 0 & $\begin{array}{ll}0 \\
0 \\
0\end{array}$ & $\begin{array}{l}\text { Maintenance costs } \\
\text { associated with LRAD } \\
\text { Used } 3 \text { days }\end{array}$ & $\begin{array}{l}3.0 \\
\text { day }\end{array}$ & & 0.000. & $\begin{array}{l}40.00 \\
120 .\end{array}$ & & $\begin{array}{ll}0.00 & \\
& 0 .\end{array}$ & 0. & 120. \\
\hline 6 & 01 & & 1ra & & & 0 & $\begin{array}{ll}0 \\
0 \\
5 \\
5\end{array}$ & $\begin{array}{l}\text { Transportation costs } \\
\text { to site, assuming } \\
500 \text { miles round trip }\end{array}$ & $\begin{array}{l}500.0 \\
\text { mile }\end{array}$ & & 0.00 0. & $\begin{array}{c}0.28 \\
140\end{array}$ & & $\begin{array}{ll}0.00 & \\
& 0 .\end{array}$ & 0. & 140. \\
\hline 7 & 01 & & $1 \mathrm{ra}$ & & & 0 & $0 T$ & $\begin{array}{l}\text { Transportation costs } \\
\text { to rent vehicle(s) } \\
\text { to transport to site }\end{array}$ & $\begin{array}{l}1.0 \\
\text { ea }\end{array}$ & & 0.00 0. & $\begin{array}{l}2000.00 \\
2000 .\end{array}$ & & 0.00. & 0. & 2000 \\
\hline 8 & 01 & & Ixa & & & 0 & $\begin{array}{rl}0 & \mathrm{I} \\
\mathrm{c} & \\
\mathrm{n}\end{array}$ & $\begin{array}{l}\text { Lodging costs for } 2 \\
\text { crew members for } 5 \\
\text { nights at } \$ 60 / \text { day }\end{array}$ & $\begin{array}{l}5.0 \\
\text { day }\end{array}$ & & $\begin{array}{l}0.00 \\
0 .\end{array}$ & $\begin{array}{c}120.00 \\
600 .\end{array}$ & & $\begin{array}{l}0.000 . \\
0 .\end{array}$ & 0. & 600. \\
\hline 9 & 01 & & 1ra & & & 0 & $\begin{array}{l}0 \\
0 \\
c \\
d\end{array}$ & $\begin{array}{l}\text { Perdiem costs for } 2 \\
\text { crew members for } 6 \\
\text { days at } \$ 40 / \text { day }\end{array}$ & $\begin{array}{l}6.0 \\
\text { day }\end{array}$ & & 0.00. & $\begin{array}{r}80.00 \\
480 .\end{array}$ & & 0.00 & 0. & 480. \\
\hline
\end{tabular}


[Items with '"' have been adfusted by Job Factor and/or Equip Factor]

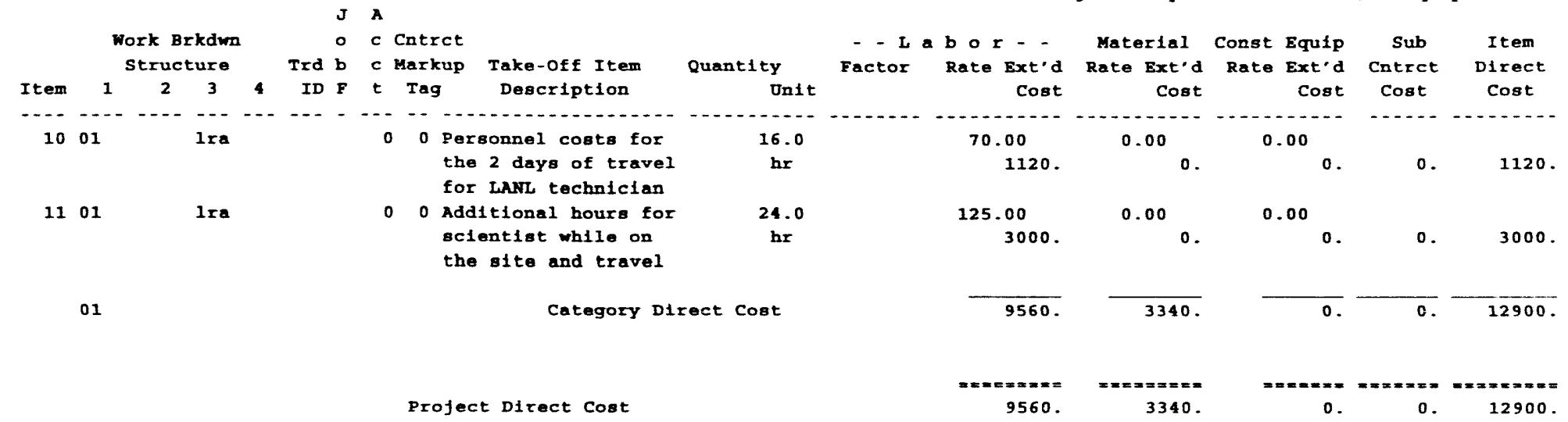


PF File: scenlrad.PR

TO File: scenlrad.TA
Martin Marletta Energy Systems

Oak R1dge. Tennessee

Sorted by WBS 1 Summarized on 2 characters

Secondary Subtotals on 0 Characters

Job Number: 1 Change order Number:

Project Title: Scenario Evaluation - Total Bxpected Cost - LRAD

$15: 11: 25$ Checked By

Est1mator: D. Douthat

Abbrev:

$11 / 4 / 93$

Location: ORNL

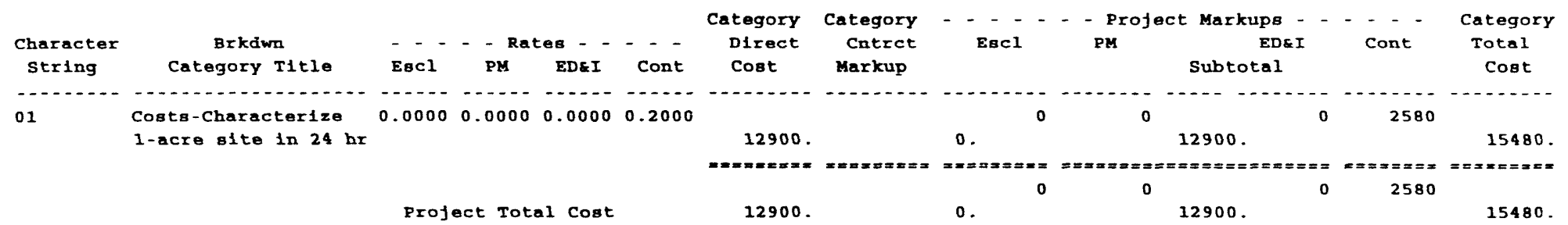


PF F1le: betacone.PR TO File: betacone.TA

\section{Martin Marietta Energy Systems \\ Oak Ridge, Tennessee}

\section{TARE-OFF EXTENSION}

Sort: WBS1 Subtotal : 4 characters

Job Number: 1

Change Order Number:

Scin. Detect.

$15: 17: 16$

Checked By:

$11 / 4 / 93$

Estimator: D. Douthat

$$
\text { Abbrev: }
$$

Location: ORNI

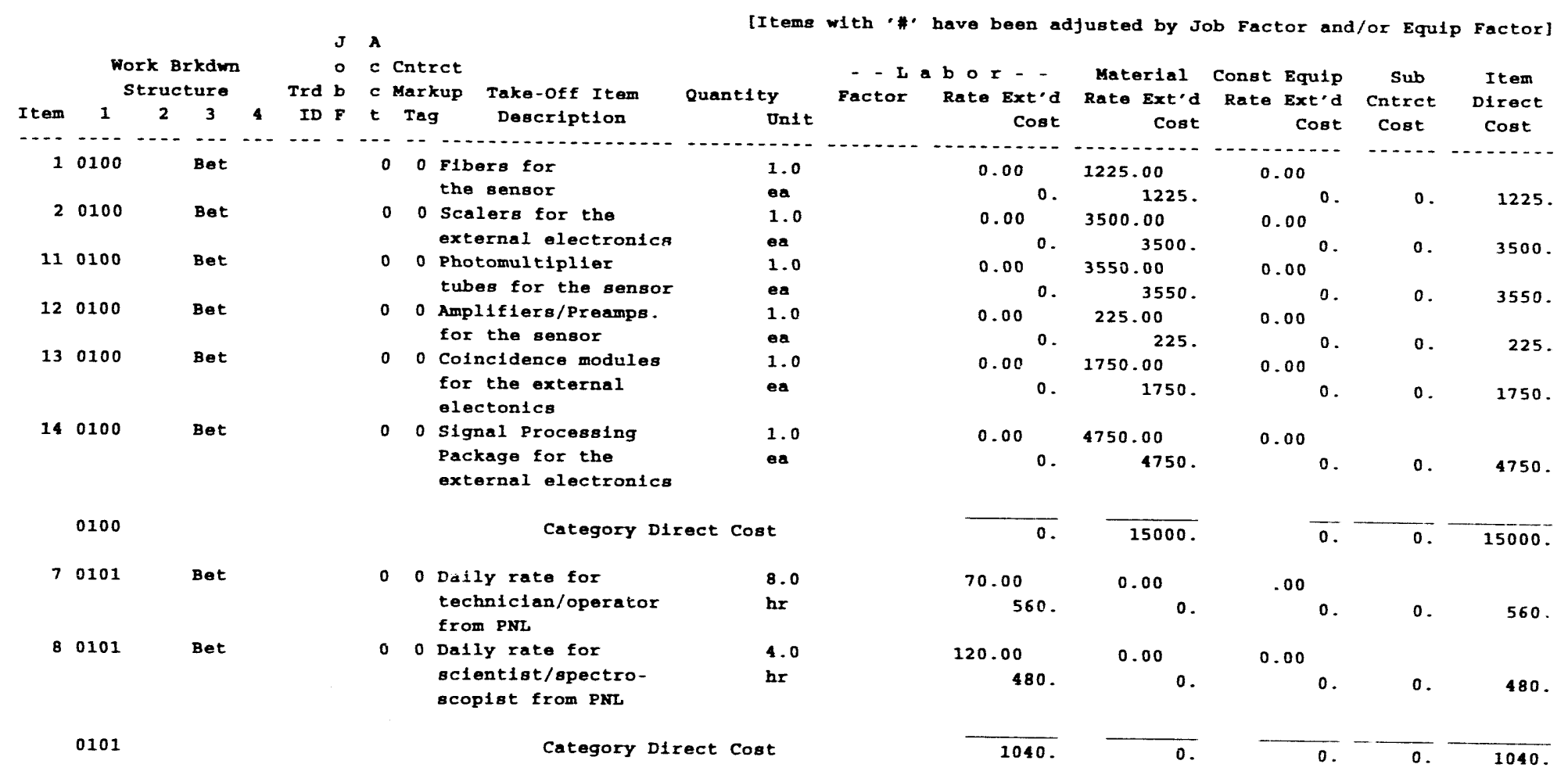




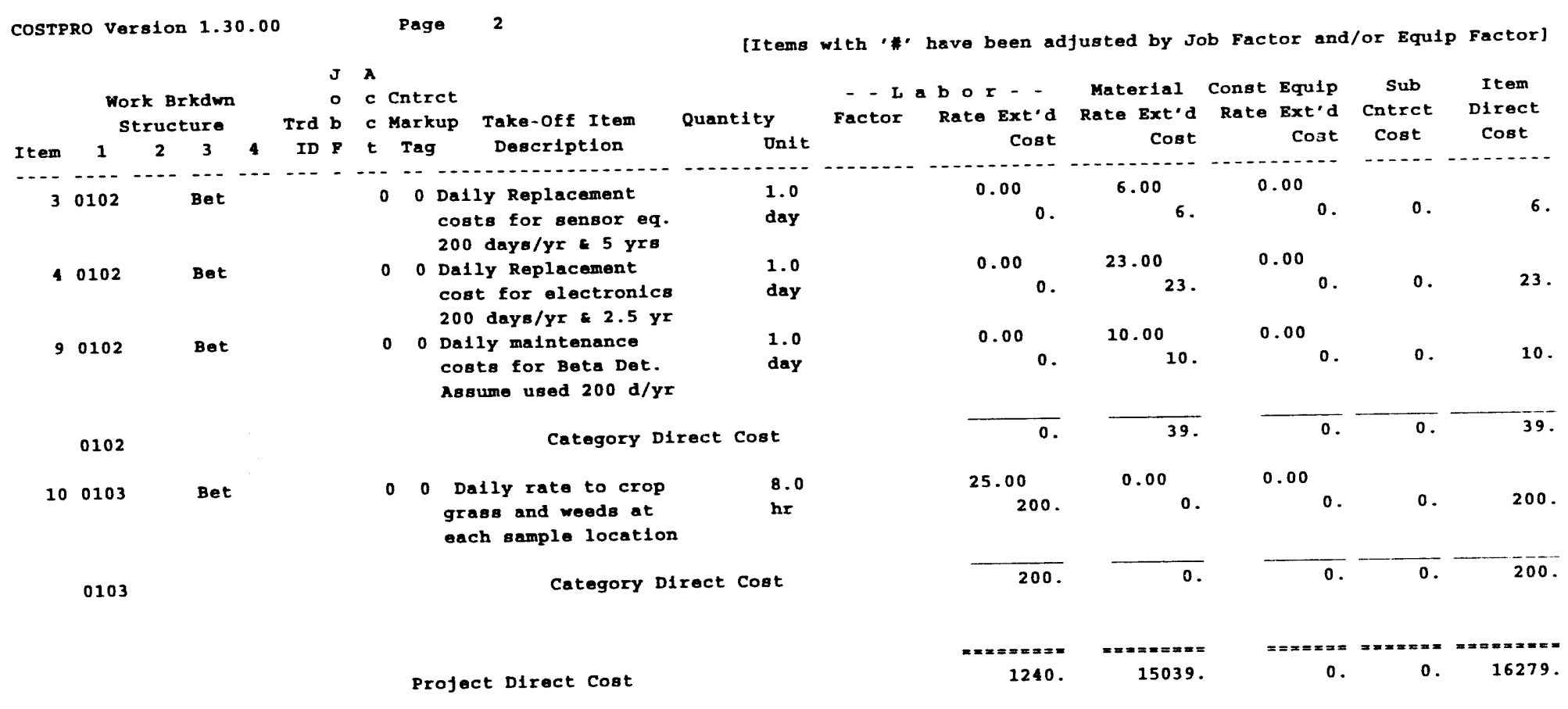


COSTPRO Version 1.30 .00

PF F1le: betacone.PR TO F110: betacone.TA
Page 3

\section{Martin Marietta Energy Systems}

Oak Ridge, Tennessee

GENERAT COST STMMSARY

\section{Sorted by WBS 1 Summarized on 4 characters}

Secondary Subtotals on 0 characters

Job Number: 1 Change Order Number:

$15: 17: 16$

$11 / 4 / 93$

Profect Title: Uranium So11s ID:Expected costs-Beta Scin. Detect.

Checked By:

Estimator: D. Douthat

Abbrev

Location: ORNL

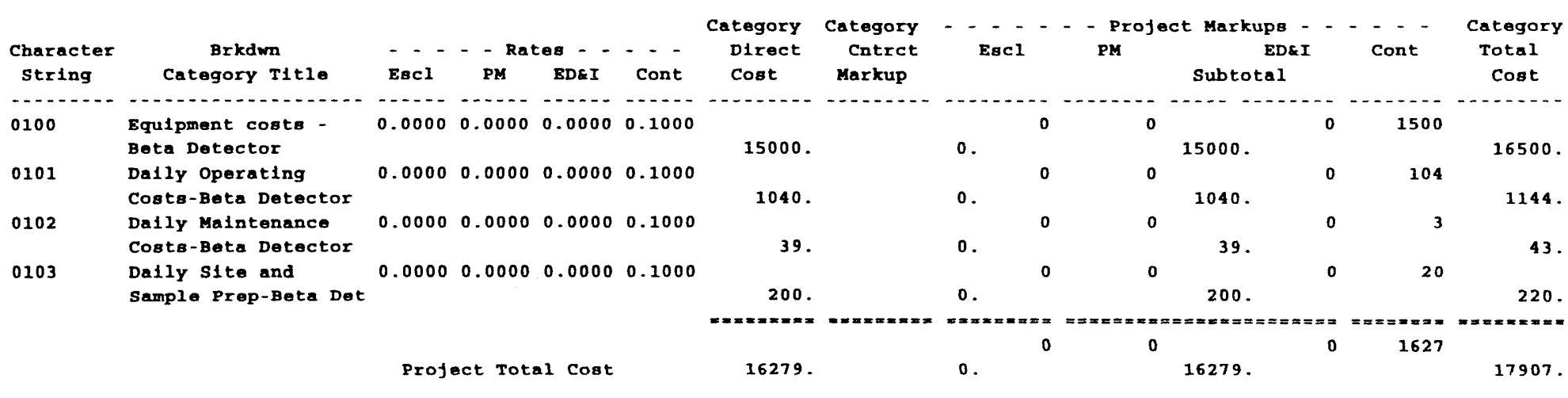


PF File: scencsbd.PR To File: scencsbd. TA
Martin Marietta Energy Systems

Oak RIdge, Tennessee

\section{TARE-OFF EXTENSION}

Sort: WBS1 Subtotal: 2 characters

Job Number: 1 Change Order Number:

Profect Titles Scenario Bvaluation - Coot Per Semple - Beta Det. Estimator: D. Douthat Abbrev

$15: 22: 47$

Checked By:

$11 / 4 / 93$

Location: ORNL

[Itemg with '" have been adjusted by Job Factor and/or Bquip Factor]

\begin{tabular}{|c|c|c|c|c|c|c|c|c|c|c|}
\hline \multirow[b]{2}{*}{ Item } & \multicolumn{4}{|c|}{$\begin{array}{c}\text { Work Brkdwn } \\
\text { Structure }\end{array}$} & \multirow{2}{*}{\multicolumn{2}{|c|}{$\begin{array}{rr} & J \\
& 0 \\
\text { Trd } & b \\
\text { ID } & F\end{array}$}} & \multirow{2}{*}{$\begin{array}{l}\mathbf{A} \\
\mathbf{c} \\
\mathbf{c} \\
\mathbf{t}\end{array}$} & $\begin{array}{l}\text { Cntrct } \\
\text { Markup }\end{array}$ & \multirow{2}{*}{$\begin{array}{l}\text { Take-Off Item } \\
\text { Description }\end{array}$} & \multirow{2}{*}{$\begin{array}{r}\text { Quantity } \\
\text { Un1 }\end{array}$} \\
\hline & 1 & 2 & 3 & 4 & & & & Tag & & \\
\hline 1 & $\begin{array}{ll}\cdots \\
01\end{array}$ & & Bet & & $\cdots$ & & 0 & $\begin{array}{rr}\cdots & - \\
0 & c \\
t \\
t\end{array}$ & $\begin{array}{l}\text { Crop grass and weeds } \\
\text { to } 1 \text { inch high for } \\
\text { the } 1 \text {-acre site }\end{array}$ & $\begin{array}{l}\text { B. } \\
\text { hr }\end{array}$ \\
\hline 2 & 01 & & Bet & & & & 0 & $\begin{array}{rl}0 & E \\
9 & \\
8\end{array}$ & $\begin{array}{l}\text { Establish sampling } \\
\text { grid s locate sample } \\
\text { gites }\end{array}$ & $\begin{array}{l}8.0 \\
\mathrm{hr}\end{array}$ \\
\hline 3 & 01 & & Bet & & & & 0 & $\begin{array}{rl}0 & c \\
t \\
t\end{array}$ & $\begin{array}{l}\text { Cost to establish } \\
\text { take approx. } 100 \\
\text { samples-pNL operator }\end{array}$ & $\begin{array}{c}16.0 \\
\mathrm{hr}\end{array}$ \\
\hline 4 & 01 & & Bet & & & & 0 & $\begin{array}{rl}0 & C \\
0 \\
F\end{array}$ & $\begin{array}{l}\text { Cost to provide } \\
\text { data reduction from } \\
\text { PNL ecientist }\end{array}$ & $\begin{array}{l}4.0 \\
h r\end{array}$ \\
\hline 5 & 01 & & Bet & & & & & $0:$ & $\begin{array}{l}\text { Maintenance costs } \\
\text { associated with beta } \\
\text { detector-used } 2 \text { days }\end{array}$ & $\begin{array}{l}2.0 \\
\text { day }\end{array}$ \\
\hline
\end{tabular}

\begin{tabular}{|c|c|c|c|c|c|}
\hline $\begin{array}{l}- \text { L a } \\
\text { Factor }\end{array}$ & $\begin{array}{r}\text { b o } x-\text { - } \\
\text { Rate Ext'd } \\
\text { Cost }\end{array}$ & $\begin{array}{r}\text { Material } \\
\text { Rate Ext'd } \\
\text { Cost }\end{array}$ & $\begin{array}{r}\text { Const Equip } \\
\text { Rate Ext'd } \\
\text { Cost }\end{array}$ & $\begin{array}{c}\text { Sub } \\
\text { Cntrct } \\
\text { Cost }\end{array}$ & $\begin{array}{l}\text { Item } \\
\text { Direct } \\
\text { Cost }\end{array}$ \\
\hline & 25.00 & 0.00 & 0.00 & & \\
\hline & 200 & 0 & 0 & 0. & 200. \\
\hline & 70.00 & 0.00 & 0.00 & & \\
\hline & 560 & 0 & 0 & 0. & 560. \\
\hline & 70.00 & 0.00 & 0.00 & & \\
\hline & 1120 & 0 . & 0. & 0. & 1120. \\
\hline & 120.00 & 0.00 & 0.00 & & \\
\hline & 480 & 0 & 0 & 0 . & 480. \\
\hline & 0.00 & 39.00 & 0.00 & & \\
\hline & 0 & 78 & 0 & 0 . & 78. \\
\hline & 2360 . & 78. & 0 . & 0 . & 2438. \\
\hline & $\begin{aligned}= & ==x== \\
& 2360 .\end{aligned}$ & 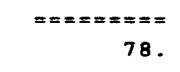 & $\begin{array}{l}== \\
0 .\end{array}$ & $\begin{array}{l}== \\
0 .\end{array}$ & 2438. \\
\hline
\end{tabular}


Oak Ridge, Tennessee

GENERAL COST SUMMARY

Sorted by wBS 1 Summarized on 2 Characters

Secondary Subtotals on 0 Characters

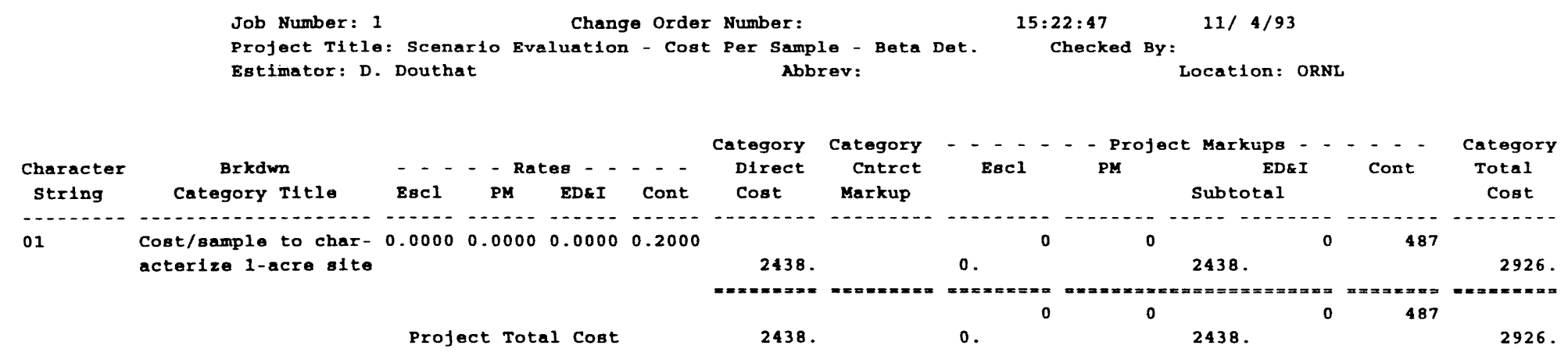


PF File: scenbeta.PR To File: scenbeta.T
Martin Marietta Energy Systems

Oak Ridge, Tennessee

\section{TARE-OFF EXTENSION}

Sort: WBS1

Subtotal: 2 characters

Job Number: 1

Change Order Number:

$15: 28: 41$

$11 / 4 / 93$

Profect Title: Scenario Evaluation - Total Expected Cost - Beta Estimator: D. Douthat

Abbrev:

IItems with '"' have been adjusted by Job Factor and/or Equip Factor

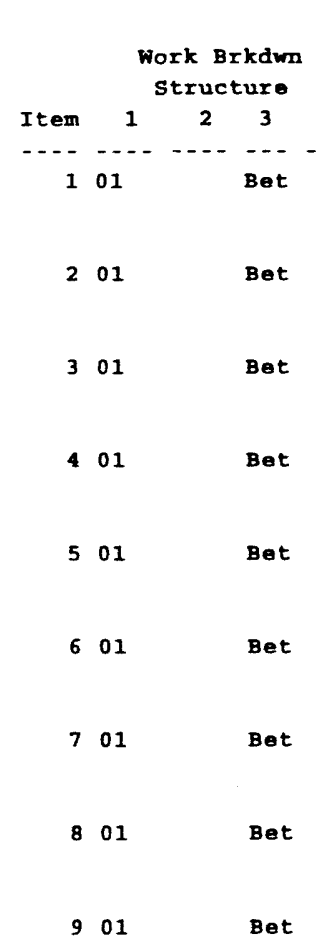

J $\mathbf{A}$

- c Cntrct

Trd b c Markup Take-off Item Quantity

- - I a b o I - -

Material Const Equip Sub Item Quantity Pactor Rate Ext'd
Cost Cost

o Crop grass and weeds to I inch high for

8.0

25.00 Cost$$
\text { the 1-acre site }
$$

- O Establish sampling grid \& locate sample

O O Cost to establish E take approx. 100 samples-PNL operator - O cost to provide dat reduction from PNL scientist

- O Maintenance costs assoctated with beta detector-used 2 days

hr

200.

0.00 Cost Cost

Transportation cost to site, assuming

8.0

hr

16.0

$\mathrm{hr}$

4.0

hr

2.0

day

0

0.00

Lodging costs for 2 crev members for 4 nights at $\$ 60 /$ day

- 0 Perdiem costs for 2 crew members for 5 days at $\$ 40 /$ day

901 Bet

- O Personnel costs for the 2 days of travel

500.0 mile

4. 0

day

5.0

day

16.0

for PNL technician
70.00

560 .

0.00

70.00 1120 .

0.00

0.00

0.0

0 .

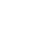

120.00

$480 . \quad 0.00$

$0.00 \quad 39.00$

78

0.00

0.00

$0.00 \quad 0.28$

0.00

0 .

$0.00 \quad 120.00$

$\begin{array}{ll} & 120.00 \\ 0 . & 480\end{array}$

0.00

$0.00 \quad 80.00$

0.00

$0 . \quad 400$.

0.00

70.00

0.00

0.00

0 .
480 .

78.

140.

480 .

400.

1120. 
J A

A cutrct

Work Brkdwn

Cntrct

Structure

d b c Mark

Take off item

[Items with '" have been adjusted by Job Factor and/or Equip Factor] Item 1 23 ID

$$
\begin{aligned}
& 0 \text { Additional hours for } \\
& \text { scientist while on } \\
& \text { the site and travel }
\end{aligned}
$$

Category Direct Cost

Profect Direct Cost

Quantity
Onit
36.0
$\mathrm{hr}$

Fact

b o r - -

Cost
120.00
4320

7800

$=x== \pm=5$

7800 .

Material Const Equip Sub Item Ext'd Rate Ext'd Cntrct Direct Cost Cost Cost Cost

0.000 .000 .04320$.

0.089

$=======$

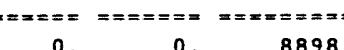

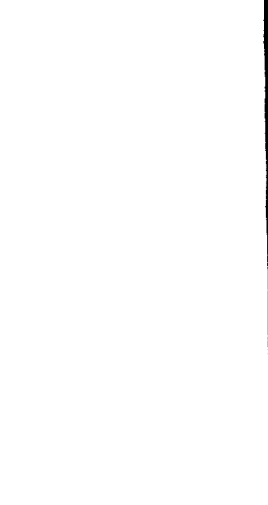


COSTPRO Version 1.30 .00

PF File: scenbeta.PR

To File: scenbeta.TA
Page

Martin Marietta Energy Systems

Oak RIdge, Tennessee

GENERAI COST SUMMARY

Sorted by WBS 1 Sumbarized on 2 Characters

Secondary Subtotals on 0 characters

Job Number: 1

Change Order Number:

ected cost - Bets

$15: 28: 41$

$11 / 4 / 93$

Profect Title: Scenario Evaluation - Total Expected Cost
Estimator: D. Douthat

Checked By:

Location: ORNI

\begin{tabular}{|c|c|c|c|c|c|c|c|c|c|c|c|c|c|c|}
\hline $\begin{array}{l}\text { Character } \\
\text { String }\end{array}$ & $\begin{array}{c}\text { Brkdwn } \\
\text { Category Titie }\end{array}$ & $\begin{array}{l}--\overline{-} \\
\text { Esc1 }\end{array}$ & $-\underset{P M}{- \text { Rat }}$ & $\begin{array}{l}\text { Ees - - } \\
\text { EDEI }\end{array}$ & $\begin{array}{c}-\overline{-} \\
\text { cont }\end{array}$ & $\begin{array}{c}\text { Category } \\
\text { D1rect } \\
\text { Cost }\end{array}$ & $\begin{array}{c}\text { Category } \\
\text { Cntrct } \\
\text { Markup }\end{array}$ & Esci & & PM & $\begin{array}{l}\text { Earkups } \\
\text { ED\&I } \\
\text { Subtotal }\end{array}$ & & Cont & $\begin{array}{c}\text { Category } \\
\text { Total } \\
\text { Cost }\end{array}$ \\
\hline 01 & Costs-Characterize & 0.0000 & 0.0000 & 0.0000 & 0.2000 & 8898 . & & 0 . & 0 & 0 & 8898 . & 0 & 1779 & 10678. \\
\hline
\end{tabular}


TAKB-OFF EXTENSION

Job Number: 1
Profect Iitle: Oranium So118 ID:Bxpected costs-In-Situ Gama Det.

Change Order Number: Estimator: D. Douthat Abbrev:

$15: 37: 19$ Checked By:

[Items with have been adfusted by Job Factor and/or Equip Factor]

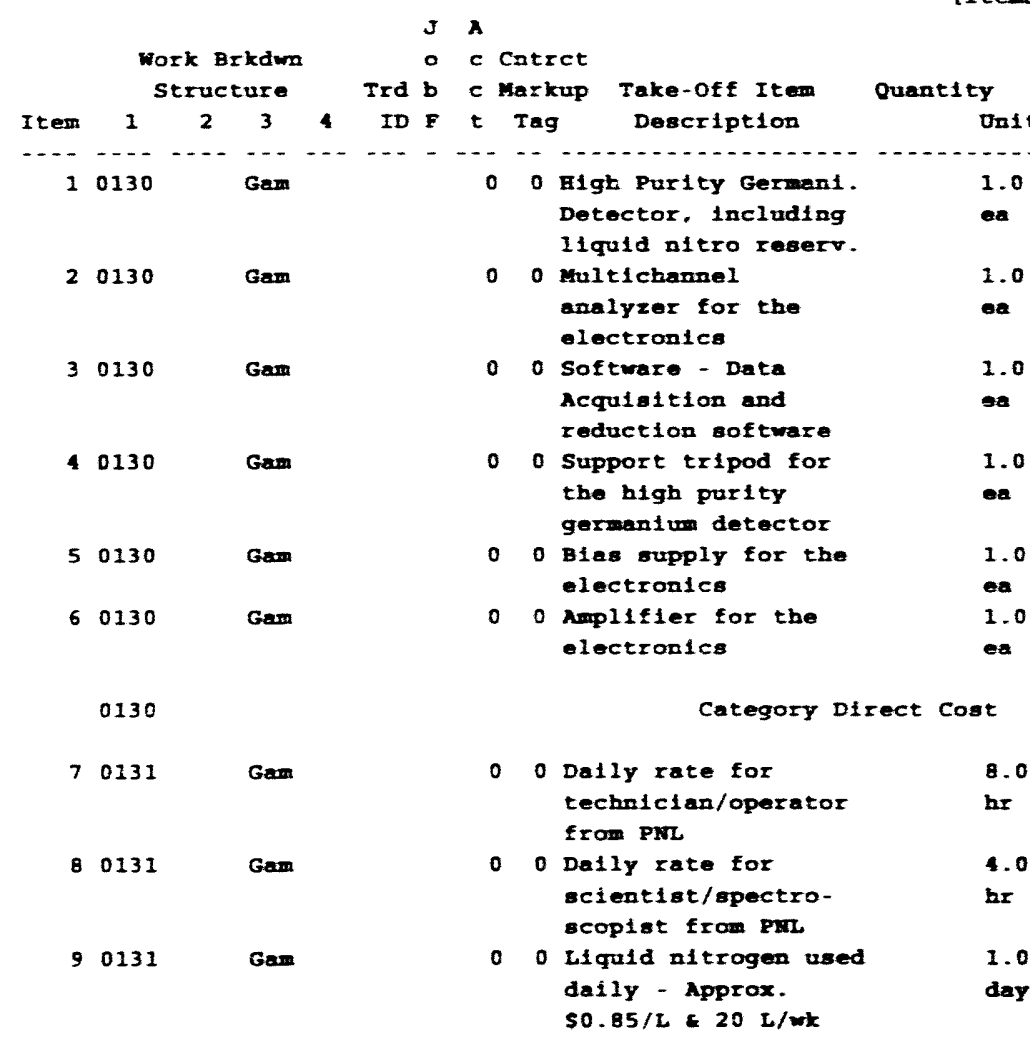

J

rd b c Markup TakeDesertption

Quantity - - I a b o r - - Materlal Const Equip Sub Item Unit Cost Cost Cost Cost Cost

.0
.0
.0
.0
.0
.0
.0
$0.00 \quad 27500.00$

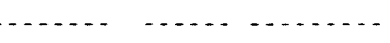

o. 27500.000.

0.00

o. 27500 11quild nitro reser

0

$0.00 \quad 4650.00$

$\begin{array}{ll} & 4650.00 \\ 0 . & 4650\end{array}$

0.00

$\begin{array}{cc}0.00 & 2000.00 \\ 0 . & 2000 .\end{array}$

0.00

$\begin{array}{ll}0.00 & 500.00 \\ 0 . & 500\end{array}$

0.00

$0.00 \quad 3025.00$

0.3025 .

$\begin{array}{lll}0.00 & 2325.00 \\ & 0 . & 2325\end{array}$

0.00

0.40000

0.00

0.00

560.

0.00

0.

o. 2325 .

120.00

0.00

0.00

o. 40000 .

daily - Approx.

1.0
day

480.

5.00

0.00

0.00

5.005.

0.00

o.

a. 560

$0 .-20$ 


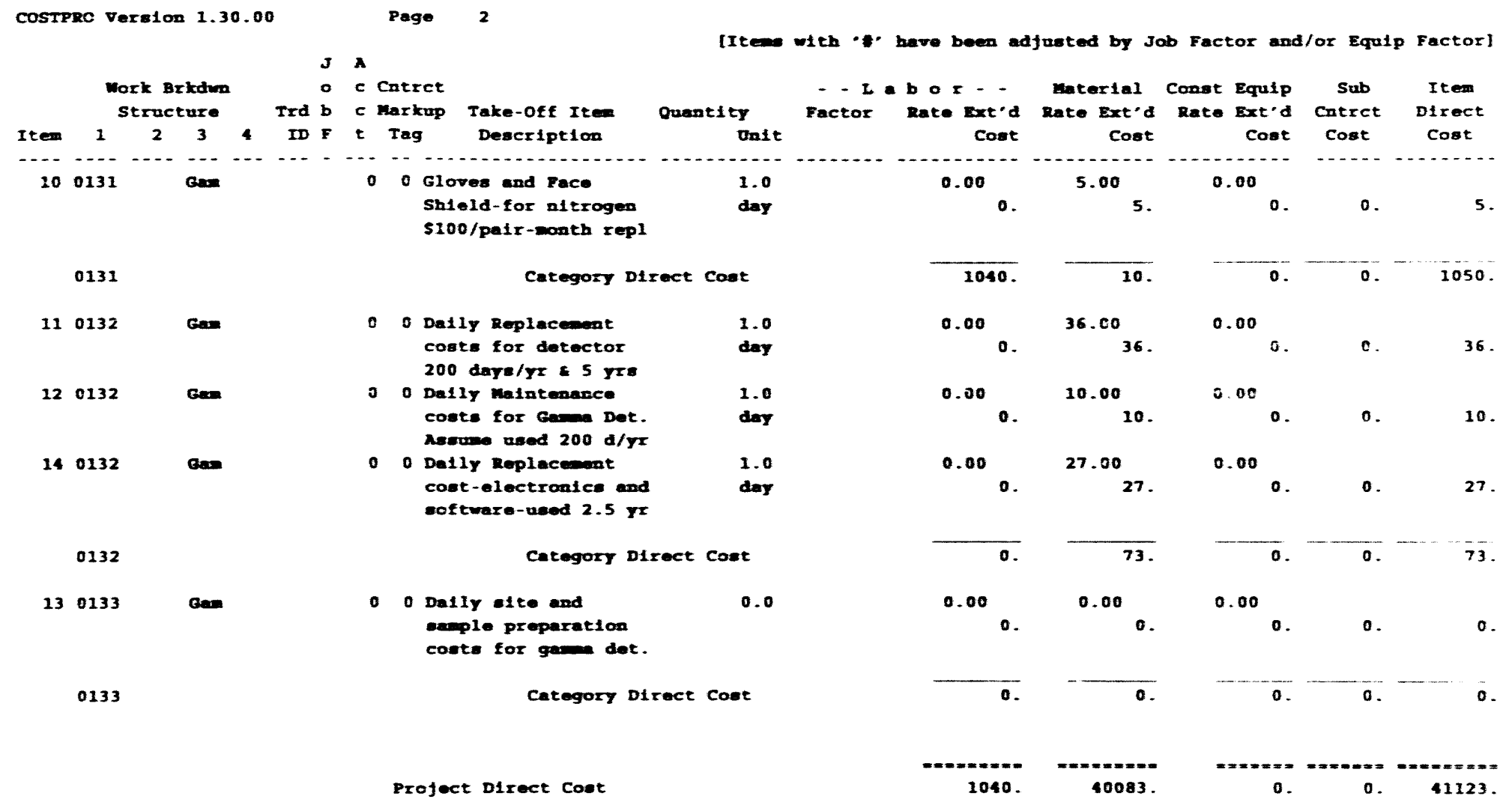


Sorted by wBS 1 Sumarixed on Characters

Secondary Subtotale on O Characters

Job Mumber: 1 Change Ordex muber: Project $T \pm 1$ : Urani
Estiesor: $D$. Douthat

In-Situ

$15: 37: 19$ checked By:

$11 / 4 / 93$

Location: ormL

\begin{tabular}{|c|c|c|c|c|c|c|c|c|c|c|c|c|c|c|}
\hline $\begin{array}{l}\text { Character } \\
\text { string }\end{array}$ & $\begin{array}{c}\text { Brkdwn } \\
\text { Category T1El0 }\end{array}$ & Eec1 & $\overline{p m}^{- \text {Rat }}$ & EDEI & cont & $\begin{array}{c}\text { Category } \\
\text { Direct } \\
\text { Cout }\end{array}$ & $\begin{array}{c}\text { Category } \\
\text { Cntrct } \\
\text { Warkup }\end{array}$ & Eaci & - & $\begin{array}{c}\text { - Profect } \\
\text { PX }\end{array}$ & $\begin{array}{c}\text { t Markup: } \\
\text { EDEI } \\
\text { Subtotal }\end{array}$ & 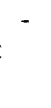 & $\begin{array}{l}-\cdot- \\
\operatorname{cont}\end{array}$ & $\begin{array}{c}\text { Category } \\
\text { Total } \\
\text { Cost }\end{array}$ \\
\hline 0130 & 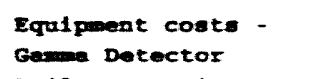 & 0.0000 & 0.0000 & 0.0000 & 0.1000 & 40000. & & 0. & 0 & & $\$ 0000$ & 0 & 4000 & 44000 \\
\hline 0131 & $\begin{array}{l}\text { Delly Operating } \\
\text { Cost -Gerese Detector }\end{array}$ & 0.0000 & 0.0000 & 0.0000 & 0.1000 & 1050. & & 0. & 0 & & 1050. & 0 & 105 & 1155. \\
\hline 0132 & $\begin{array}{l}\text { Dally Malntenance } \\
\text { Costs-Gasm Detector }\end{array}$ & 0.0000 & 0.0000 & 0.0000 & 0.1000 & 73. & & o. & 0 & 0 & & 0 & 7 & 80. \\
\hline
\end{tabular}


COSTPRo Verston 1.30 .00

PF File: scencsgd. PR To File: scencsgd.TA martin Marletta Energy Systems

Oak RIdge. Tempesseee

\section{TAKE-OFP ExTEISIOI}

Sort: WBS1 Subtotal: 2 characters

Job Number: 1
Project Ifte: Scenario Evaluation Order Mumber:

Project Ifte: Scenar
Estimator: D. Douthat

abbrev:
$15: 46: 4$

$11 / 4 / 93$

Checked by:

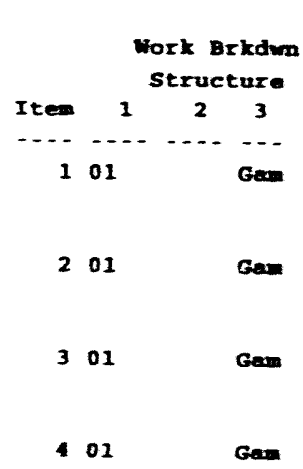

01
J A Cotrct

Trd b c Cntrce

Trd b c Markup Take-otf Ite-

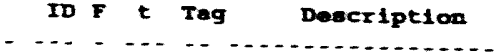

- 0 Eatabliah ampling grid a locate sample ates

Ouentity
Ondt
8.0
hx
3.0
hx
2.0
hx
1.0
day

- I a b o - - Material Const Equip Sub Item Factor Rate Ext'd Rate Ext'd Rate Ext'd Crirct Direct $\begin{array}{ccccc}\text { Cost } & \text { Cost } & \text { Cost Cost Cost }\end{array}$

70.00

o cost to estabilsh saiples-prt. operator

560

0.00

0.00 data reduction from PQI sclentiat

- O Maintenance costa for the gavea detector-used 1 day 70.00

$0.00 \quad 0.00$

210.00 .220$.

120.00

240 .

0.00

0.00

0.00

o. $\quad 73.00$

73.

0.00

o. 0

240.

Category D1rect Cost

1010

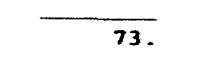

Profect Direct Cost $==-=x= \pm=$

1010.

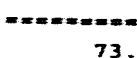

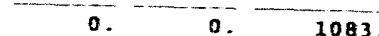

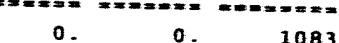


Martin Marletta Energy Systems

Oak Ridge. Temessee

GEMERAL COST SUMERRY

Sorted by wBS I

Secondary Subtotals on 0 Characters

Job Number: 1

Change Order Number:

unarized on 2 Characters Profect Title: Scenar1o Bvaluation - Cost Per Sampio - Gama Det. Estimator: D. Douthat Abbrev:

$15: 46=4$ Checked By:

$11 / 4 / 93$

Location: ORNI

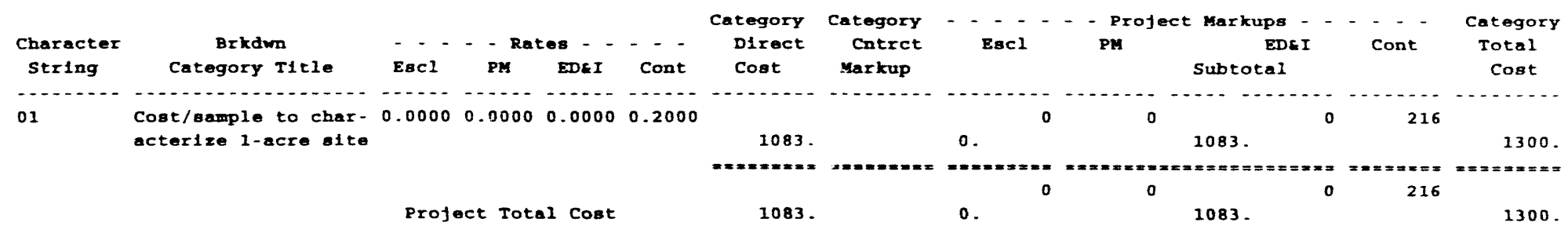


PF File: scengamm.PR
Martin Marletta Energy Systems

Oat Ridge, Tennesses

\section{TAKB-OFF EXTERSION}

Sort: WBS1 Subtotal: 2 characters

Change Order Number:

$15: 49: 38 \quad 11 / 4 / 93$

Job Number: 1

Checked By:

Estimator: D. Douthat Evaluation - Total Expected Cog

Location: ORNI

[Items with ' have been adjusted by Job Factor and/or Equip Factor]

\begin{tabular}{cccc} 
& \multicolumn{3}{c}{$\begin{array}{c}\text { Work Brkdwn } \\
\text { Structure }\end{array}$} \\
Item & 1 & 2 & 3 \\
1 & 01 & Gam \\
2 & 01 & & Gam \\
3 & 01 & \\
4 & 01 & Gam \\
5 & 01 & Gam \\
6 & 01 & Gam \\
7 & 01 & Gam \\
8 & 01 & Gam \\
9 & 01 & Gam
\end{tabular}

o c catrct

C Markup Take-off Item Quant1ty

$\begin{array}{ccccc}\text { - I a b o r - - Material Const Equip } & \text { Sub } & \text { Item } \\ \text { Factor Rate Ext'd Rate Ext'd Rate Ext'd Crtrct } & \text { Direct }\end{array}$ grid s sampling

8.0

* locate sample

0.00 Cost Cost Cost Cost

Cost to establish = take approx. 20 samples-PNL operator

0 Cost to provide data reduction from

3.0

$$
\text { PNI scientist }
$$

- O Maintenance costs for the gamma detector-used 1 day

- O Transportation costs to site, assuming 500 miles round trip

0 Lodging costs for 2 crew members for 3 gights at $\$ 60 /$ day

- O perdiem costs for 2 rew members for 4 days at \$40/day

0 Additional hours for technictan while on the site and travel

o Additional hours for scientist while on the site and travel

\begin{tabular}{|c|c|c|c|c|c|}
\hline 70.00 & 0.00 & 0.00 & & & \\
\hline 210. & 0. & & 0. & 0. & 210. \\
\hline 120.00 & 0.00 & 0.00 & & & \\
\hline 240 & 0 & & 0. & 0. & 240. \\
\hline 0.00 & 73.00 & 0.00 & & & \\
\hline 0. & 73 & & 0. & 0. & 73. \\
\hline 0.00 & 0.28 & 0.00 & & & \\
\hline 0 . & 140. & & 0. & 0 . & 140. \\
\hline 0.00 & 120.00 & 0.00 & & & \\
\hline 0. & 360 & & 0. & 0. & 360. \\
\hline 0.00 & 80.00 & 0.00 & & & \\
\hline 0. & 320. & & 0 . & 0. & 320. \\
\hline 70.00 & 0.00 & 0.00 & & & \\
\hline 1470. & 0. & & 0. & 0 . & 1470. \\
\hline 120.00 & 0.00 & 0.00 & & & \\
\hline 3600 & 0 & & 0. & 0. & 3600. \\
\hline 6080 & 893. & & 0. & 0. & 6973. \\
\hline
\end{tabular}


Martin Marietta Energy Systems

Oak R1dge, Tennessee

GENERAL COST SUMMARY

Sorted by WBS 1 Summarized on 2 Characters

Secondary Subtotals on 0 Characters

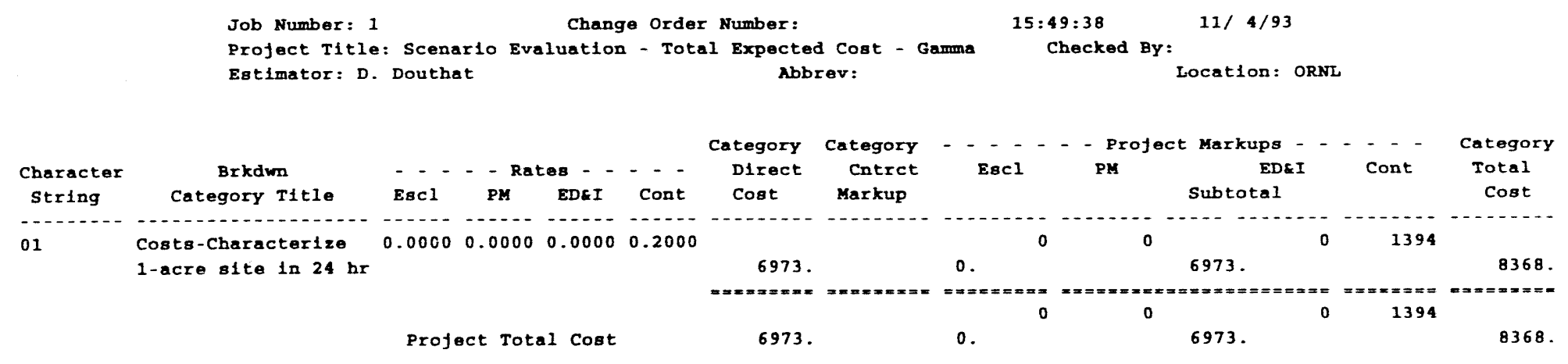


PF F1le: 1 cpcone.PRF TO F1le: 1cpcone.TAR
Martin Marletta Energy Systems

Oak Ridge, Tennessee

\section{TAKE-OFF EXTENSION}

Sort: WBS1 Subtotal : characters

Job Number: 1

Change Order Number:

Job Number: 1

Profect Title: Uranium So1ls ID: Expected costs - MDLEST LA-ICP/ABs Estimator: D. Douthat

\section{$15: 55: 38 \quad 11 / 4 / 93$}

Checked By:

Location: ORNL

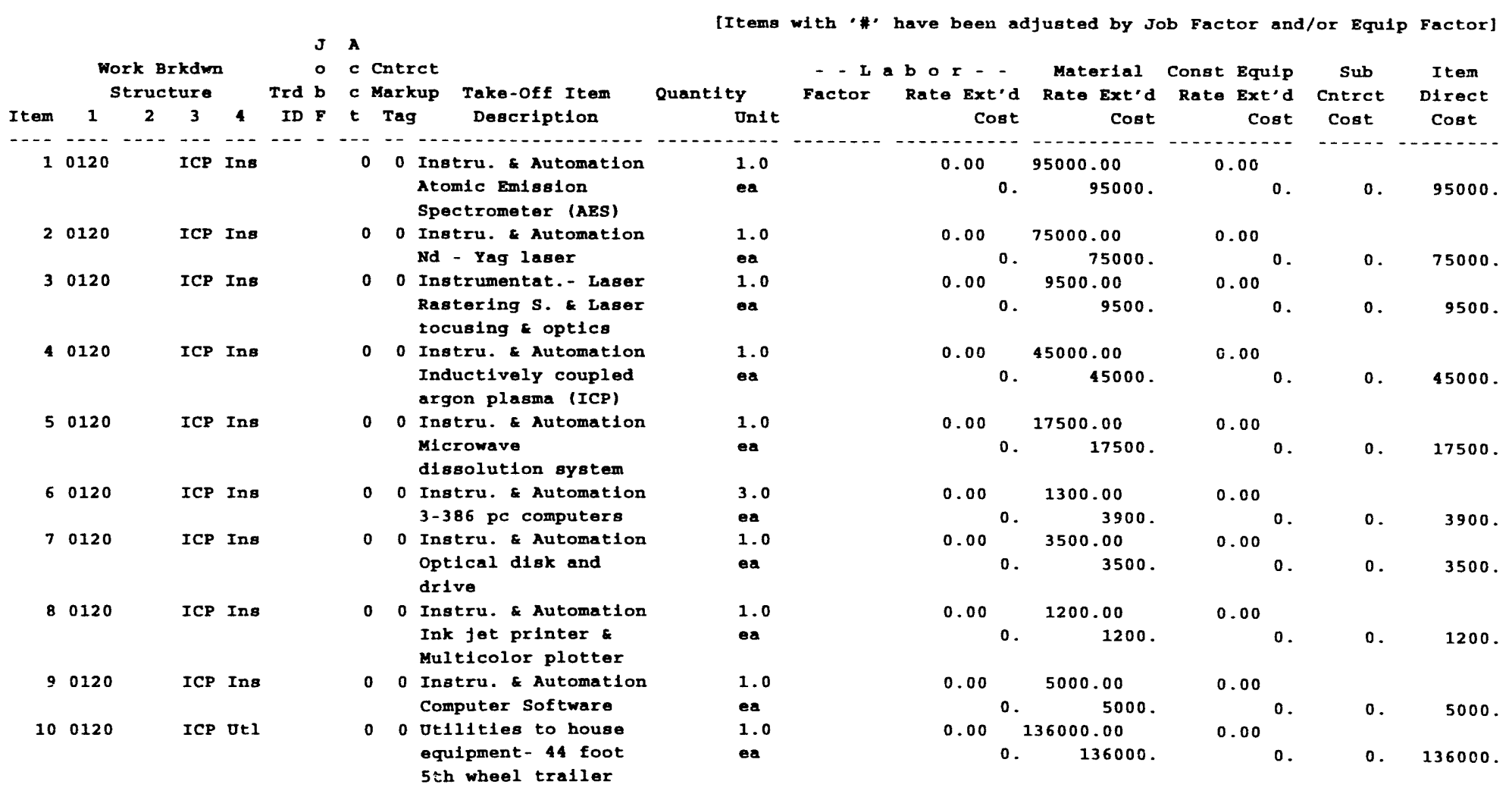




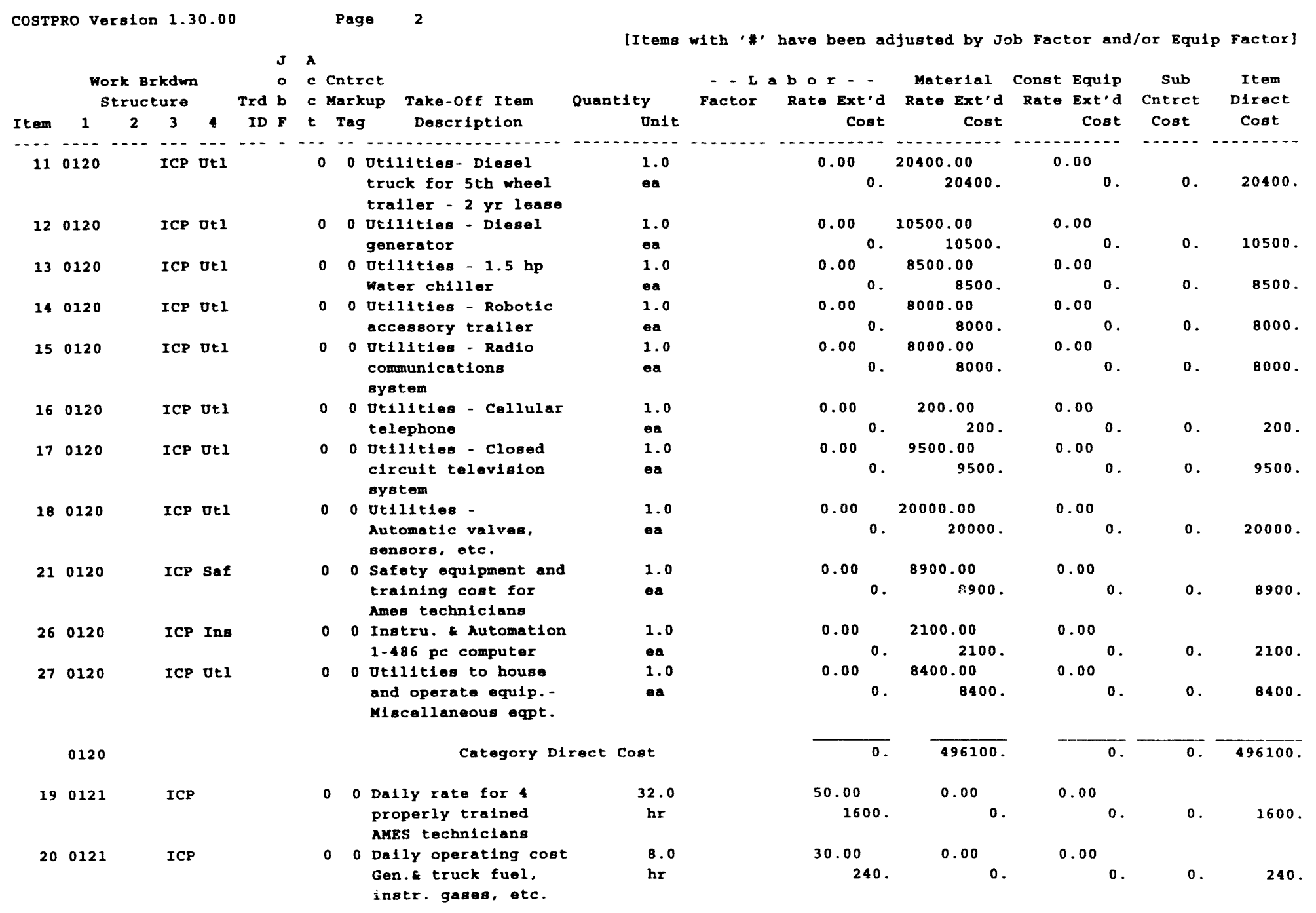




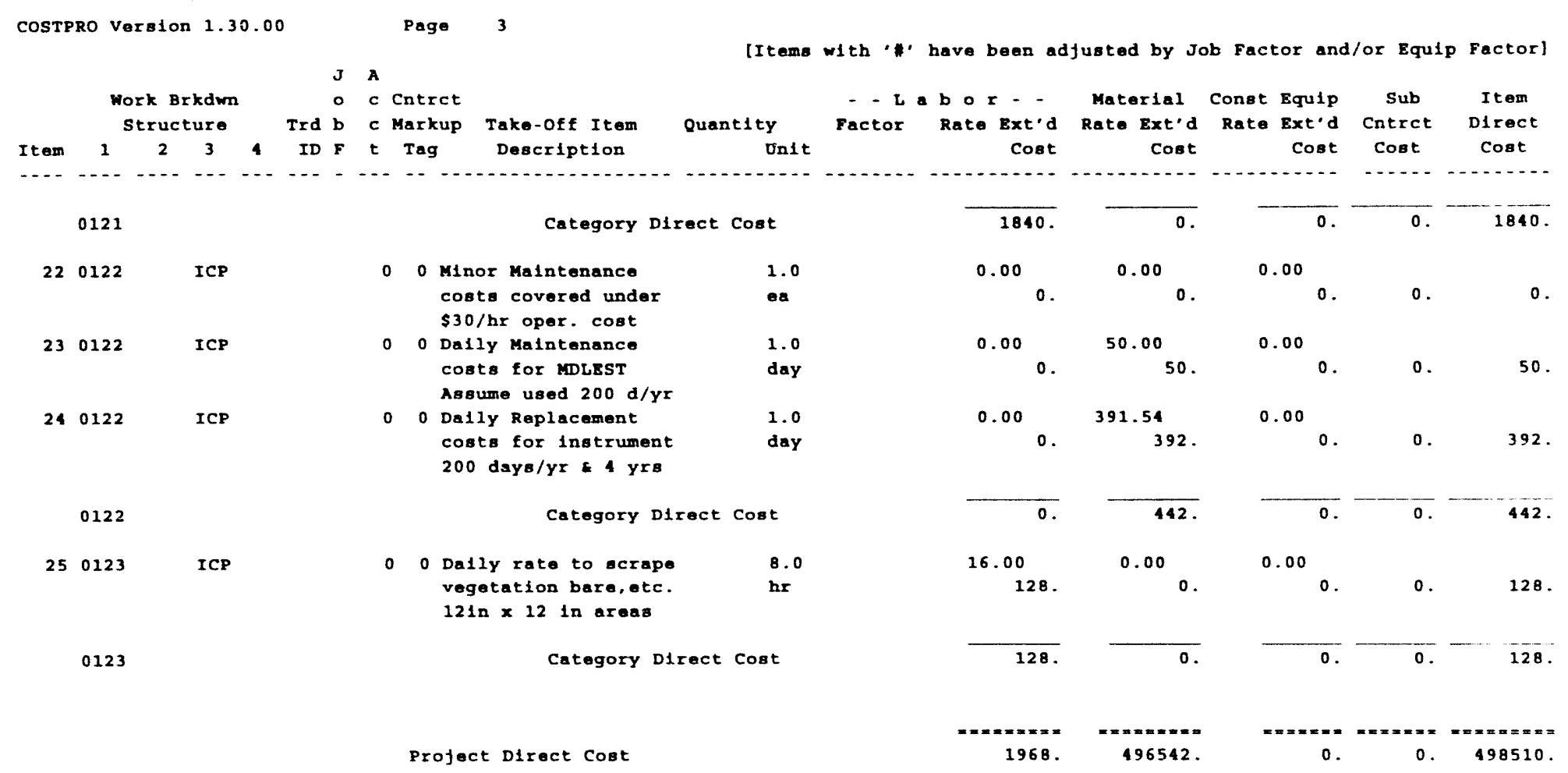




\section{Martin Marietta Energy Systems}

Oak Ridge, Tennessee

GENERAL COST SURRARY

Sorted by WBS 1

$$
\text { Summarized on } 4 \text { Characters }
$$

Secondary Subtotals on 0 Characters $\begin{array}{ll}\text { Job Number: } 1 & \text { Change Order Number: } \\ \text { Profect Title: Oranium So1ls ID:Expected costs- MDLEST LA-ICP/AES }\end{array}$ Est1mator: D. Douthat
$15: 55: 38$ Checked By
$11 / 4 / 93$

Location: ORNI

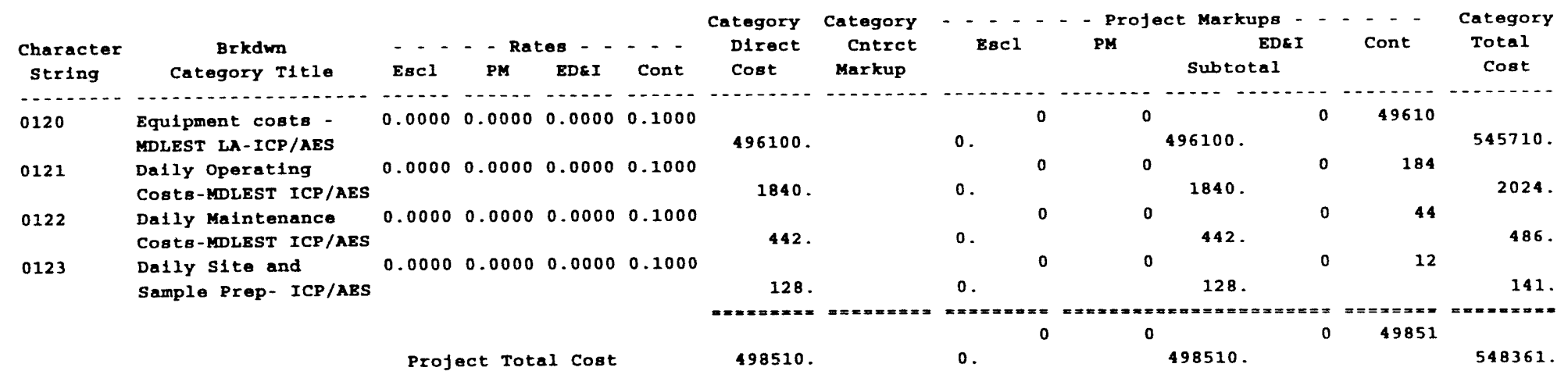

Profect Total Cost

498510

0.

498510.

548361. 
PF F1le: scencsic. PR

TO File: sconcotc TA
Martin Marletta Energy Systems

Oak Ridge, Tennessee

\section{TARB-OFF EXTENSION}

Subtotal: 2 characters

Change Order Number:

Job Number: 1

$15: 57: 10$

Checked By:

Profect Title: Scenario Evaluation - Cost Per Sample - LA-ICP/AES Estimator: D. Douthat

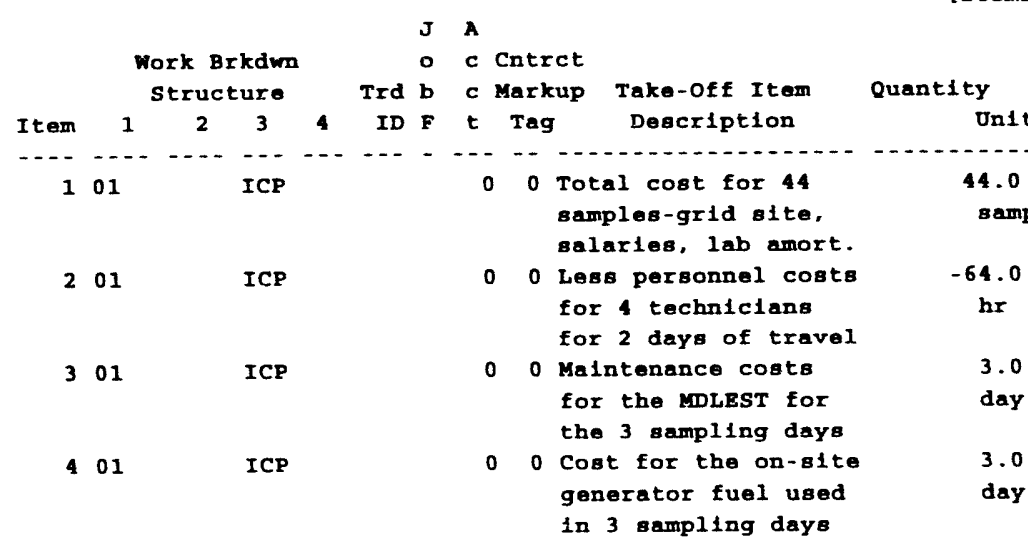

01
Category Direct Cost

Profect Direct Cost 
Oak Ridge, Tennessee

GENERAL COST SUMMARY

Sorted by WBS 1 Summarized on 2 Characters

Secondary Subtotals on 0 Characters

Job Number: 1

Change Order Number:

$15: 57: 10$
Checked BY

$11 / 4 / 93$

Profect Title: Scenario Evaluation - Cost Per Sample Abbrev:

Location: ORNL

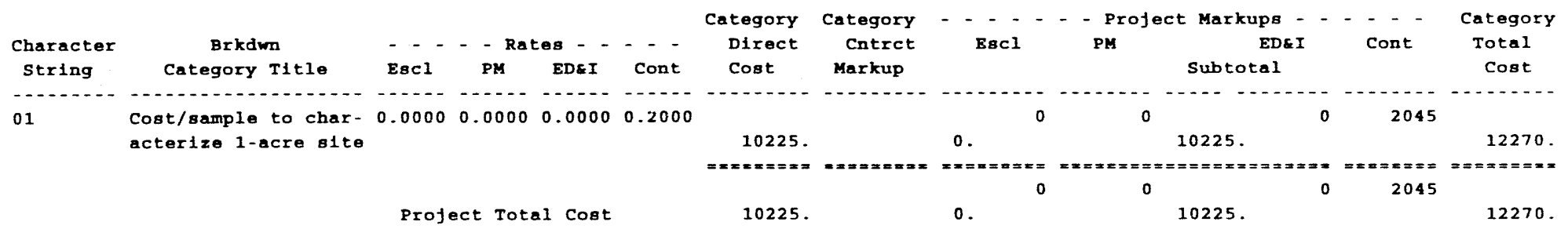

10225 .

0.

12270 
PF F1le: Bcentcp.PRF TO File: scentcp. TAK

\section{Martin Marietta Energy Systems}

Oak Ridge, Tennessee

\section{TAKB-OFF EXTENSION}

Sort: wBS1

Subtotal : 2 characters

Job Numbar: 1 Change Order Number:

Profect Title: Scenaric Evaluation-Total Expected Cost-LA-ICP/ABS Bstimator: D. Douthat Abbrev:

$15: 58: 37$

Checked $\mathrm{By}$

$11 / 4 / 93$

Location : ORNI

IItems with '\#' have been adjusted by Job Factor and/or Equip Factor

\begin{tabular}{cccc}
\multicolumn{1}{c}{$\begin{array}{c}\text { Work Brkdwn } \\
\text { Structure }\end{array}$} \\
Item & 1 & 2 & 3 \\
\hline 1 & 01 & & ICP \\
2 & 01 & & ICP \\
3 & 01 & & ICP \\
4 & 01 & & ICP \\
5 & 01 & ICP \\
6 & 01 & ICP \\
7 & 01 & ICP
\end{tabular}

01
J $\mathbf{A}$

- c Cntrct

rd b c Markup Take-off Item

Onit - - I a b o r - - Material Const Equip cub
Item Cost Cost Cost Cost Cost

-
-.... O Total cost for 44 samples-grid Bite.

samp $0.00 \quad 300.00$

13200 . salaries, lab amort. 4.0 crew members for 4 day nights at $\$ 60 /$ day - O Perdiem costs for $4 \quad 5.0$ crew members for 5

5.0
day days at $\$ 40 /$ day - O Transportation costs 500.0 for MDLEST, assuming 3.0 - O Cost for the on-site generator fuel used

3.0 in 3 sampling days

day

- O Transportation for 500 miles round trip

500.0

o Maintenance costs for the MDLEST for
the 3 sampling days

3.0
day sampling days

Category Direct Cost

\begin{tabular}{|c|c|c|c|c|}
\hline 0.00 & 240.00 & 0.00 & & \\
\hline 0 & 960. & & 0 . & 960. \\
\hline 0.00 & 160.00 & 0.00 & & \\
\hline 0 & 800 & & 0. & 800 \\
\hline 0.00 & 0.28 & 0.00 & & \\
\hline 0 & 140 & c & 0. & 140. \\
\hline 0.00 & 25.00 & 0.00 & & \\
\hline 0 & 75 & & 0. & 75. \\
\hline 0.00 & 0.28 & 0.00 & & \\
\hline 0 & 140. & & 0. & 140. \\
\hline 0.00 & 50.00 & 0.00 & & \\
\hline 0 & 150 & & 0. & 150. \\
\hline & 15465. & & 0. & 15465. \\
\hline
\end{tabular}

15465.

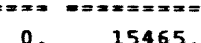


COSTPRO Version 1.30 .00

PF File: scentcp.PRF TO File: scentcp.TAR
Page 2

\section{Martin Marietta Energy Systems} Oak Ridge, Tennessee

Sorted by wBS 1

Summarlzed on 2 characters

secondary Subtotals on 0 Characters

Job Number: 1 Change Order Number:

Chation-Total Expected Cost-IA-ICP/ABS

$15: 58: 37$ Checked By:

Profect Title: Scenarto Evaluation-Total Bxpect

Bstimator: D. Douthat

Abbrev:

Location: ORML.

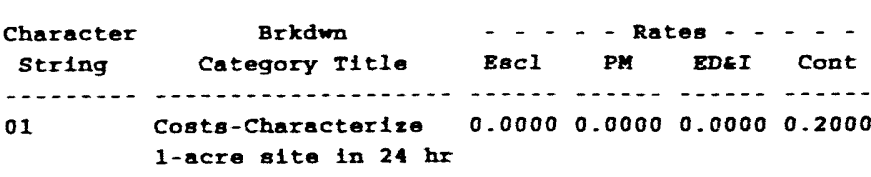

15465 .

Profect Total cost

(...........

$=-==-==$

0.

PM

Markups EDEI Cont Total

Subtotal Cost
Cost 15465. 3093 18558 0 15465.

18558 
ORNL/TM-12449

\section{INTERNAL DISTRIBUTION}

1. M.R. Ally

2. A.Q. Armstrong

3. B.A. Berven

4.6. D.M. Douthat

7. C.W. Francis

8. C.W. Gehrs

9. S.Y. Lee

10. A.P. Malinauskas

11. C.W. McGinn

12. D.B. Miller

13. S.T. Purucker

14. C.C. Travis

15. J.H. Wilson

16. Central Research Library

17-18. Laboratory Records Dept.

19. Laboratory Records, RC

20. ORNL Patent Office

\section{EXTERNAL DISTRIBUTION}

21. M. Anderson, Ames Laboratory, Environmental Technology Development, 125 S. 3rd St. - Sherman Building, Ames, IA 50010-6739

22. J.C. Cunnane, Argonne National Laboratory, 9700 South Cass Avenue, Argonne IL 60439

23. D. Gerrick, WEMCO, P.O. Box 398704, Cincinnati, OH 45239

24. D. Herman, WEMCO, P.O. Box 398704, Cincinnati, OH 45239

25-29. P.G. Kaplan, Division 6312, Sandia Nati mal Laboratories, Albuquerque, NM 87185

30. D. Layton, Lawrence Livermore National Laboratory, P.O. Box 5507, L-453, Livermore, CA 94550

31. D. MacArthur, Los Alamos National Laboratory, MS J562. Los Alamos, NM 87545

32. M. Malone, U.S. Department of Energy, EM-551 Trevion II Blvd., Washington, DC 20585-0002

33. D. Morris, INC-Il Actinide Team, MS C345, Los Alamos National Lahoratory, Los Alamos, NM 87545

34-36. K. Nuhfer, WEMCO, P.O. Box 398704, Cincinnati, OH 45239

37. D.L. Perry, Lawrence Berkeley Laboratory, MS 70A-1150, Berkeley, CA 94720

38. R.R. Ryan, LANL-INC-4, MS C346, P.O. Box 1663, Los Alamos, NM 87545

39. A. Schilk, Pacific Northwest Laboratory, P.O. Box 999, MS P8-01, Richland WA 99352

40. J. Schwing, WEMCO, P.O. Box 398704, Cincinnati, OH 45239

41. R. Stead, WEMCO, P.O. Box 398704, Cincinnati, OH 45239

42. L. Stebbins, WEMCO, P.O. Box 398704, Cincinnati, OH 45239

43. T.M. Sullivan. Brookhaven National Laboratory, Building 830, Upton, NY 11973

44. V.C. Tidwell, Sandia National Laboratories, MS 6315, P.O. Box 5800, Albuquerque, NM 87185 
45. Office of Assistant Manager for Energy Research and Development, U.S. Department of Energy. Oak Ridge Operations Office, P.O. Box 2001. Oak Ridge, TN 37831 -8600

46-47. Office of Scientific \& Technical Information, P.O. Box 62. Oak Ridge. TN 37831 

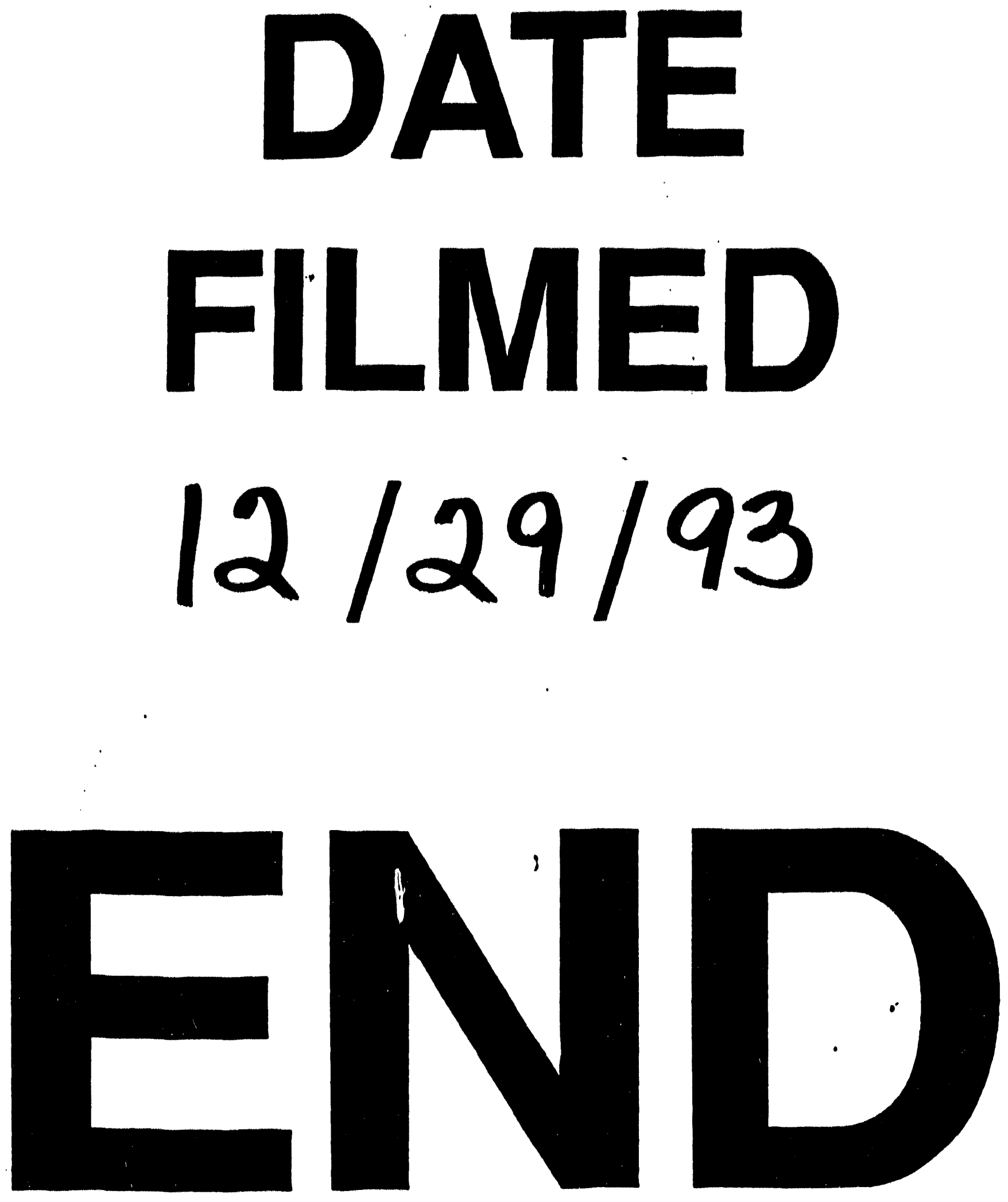
$$
\text { 每, }
$$

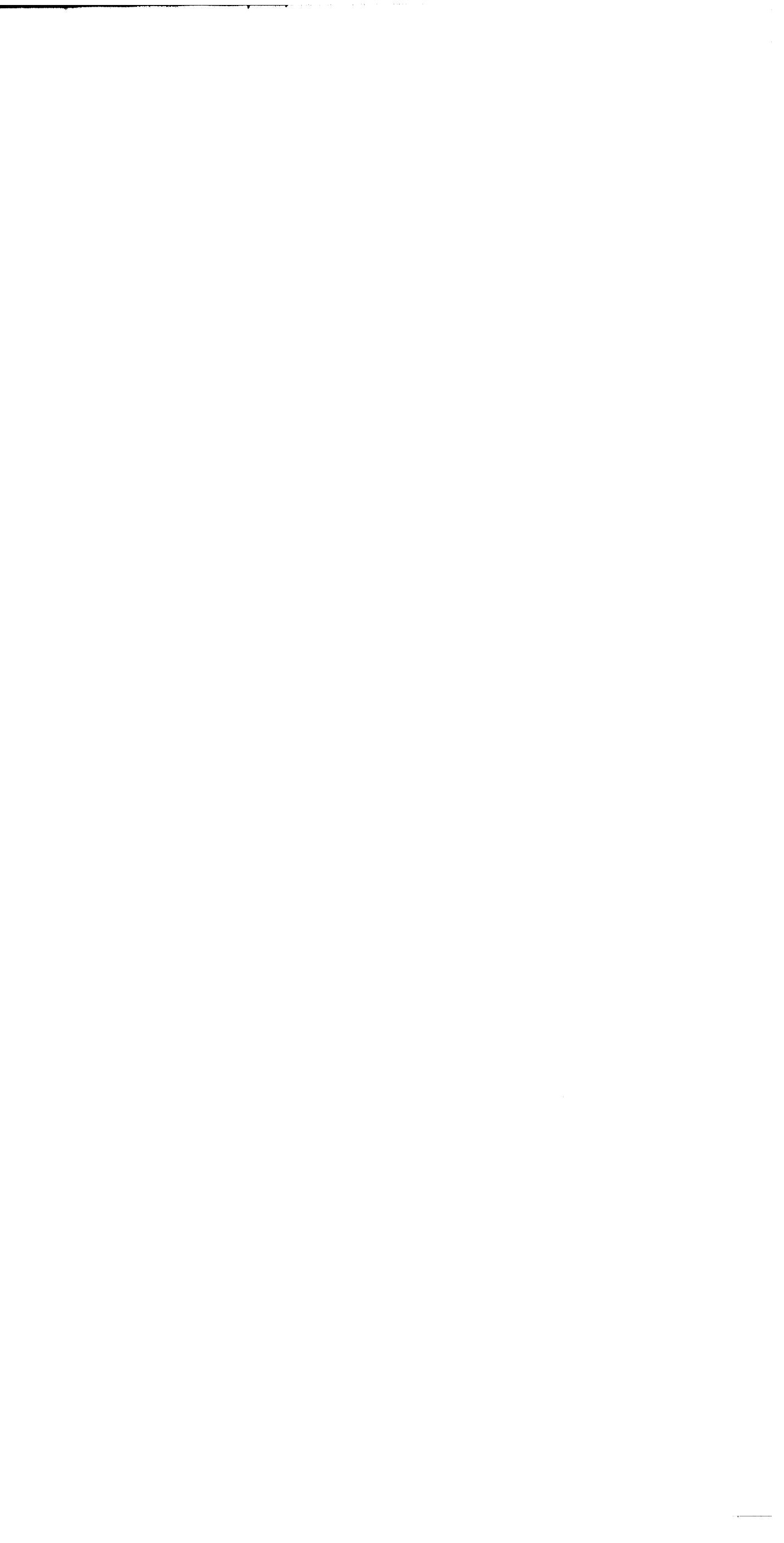

